\title{
TITLE:
}

\section{A Triggering Mechanism for Rapid Intensification of Tropical Cyclones}

$\operatorname{AUTHOR}(\mathrm{S})$ :

Miyamoto, Yoshiaki; Takemi, Tetsuya

CITATION:

Miyamoto, Yoshiaki ... [et al]. A Triggering Mechanism for Rapid Intensification of Tropical Cyclones. Journal of the Atmospheric Sciences 2015, 72: 2666-2681

ISSUE DATE:

2015-07

URL:

http://hdl.handle.net/2433/217987

RIGHT:

(C) 2015 American Meteorological Society 


\title{
A Triggering Mechanism for Rapid Intensification of Tropical Cyclones
}

\author{
YOSHIAKI MIYAMOTO \\ RIKEN Advanced Institute for Computational Science, Kobe, Japan \\ TETSUYA TAKEMI \\ Disaster Prevention Research Institute, Kyoto University, Uji, Japan
}

(Manuscript received 8 July 2014, in final form 1 April 2015)

\begin{abstract}
Triggering processes for the rapidly intensifying phase of a tropical cyclone (TC) were investigated on the basis of numerical experiments using a three-dimensional nonhydrostatic model. The results revealed that the rapid intensification of the simulated TC commenced following the formation of a circular cloud, which occurred about $12 \mathrm{~h}$ after the TC became essentially axisymmetric. The circular cloud (eyewall) evolved from a cloudy convective cell that was originally generated near the radius of maximum wind speed (RMW). The development of the convective cell in the eyewall was closely related to the radial location of the strong boundary layer convergence of axisymmetric flow. The radius of maximum convergence (RMC) was small relative to the RMW when the TC vortex was weak, which is consistent with the boundary layer theory for a rotating fluid system on a frictional surface. As the TC intensified, the RMC approached the RMW. An eyewall was very likely to form in the simulated TC when the RMC approached the RMW. Because the RMC is theoretically determined by a Rossby number defined by the maximum tangential velocity, RMW, and Coriolis parameter, a series of numerical experiments was conducted by changing the three parameters. The results were consistent with the hypothesis that intensification occurs earlier for larger Rossby numbers. This finding indicates that initial TC vortices with larger Rossby numbers are more likely to experience rapid intensification and, hence, to evolve into strong hurricanes.
\end{abstract}

\section{Introduction}

Tropical cyclones (TCs) often undergo two intensification phases, which have different rates of change in TC intensity (e.g., Sitkowski and Barnes 2009). During the initial stage, TCs slowly intensify for tens of hours, before some enter the next stage, which has a faster rate of intensification. This fast spin-up phase is often referred to as rapid intensification (RI). Kaplan and DeMaria (2003) conducted statistical analyses of RI, defining it as a period during which the intensification rate is greater than $15.4 \mathrm{~m} \mathrm{~s}^{-1}(24 \mathrm{~h})^{-1}$. They demonstrated that all category 4 or 5 hurricanes experience $\mathrm{RI}$ at least once during their lifetime and that once a TC experiences RI, the TC attains a strong intensity.

Corresponding author address: Yoshiaki Miyamoto, RIKEN Advanced Institute for Computational Science, 7-1-26 Minamimachi, Minatojima, Chuo-Ku, Kobe, Hyogo 651-0084, Japan.

E-mail: ymiyamoto@riken.jp
One possible mechanism for RI is positive feedback between convective heating around the center of the vortex and vortex-scale motion (Charney and Eliassen 1964; Ogura 1964; Ooyama 1969). Converging flow induced by surface friction enhances upward motion that results in convective heating, the heating produces an inward transportation of moisture and angular momentum from the outside, and the tangential velocity then accelerates, which subsequently increases the convergence. Emanuel $(1986,1995,1997)$ proposed that a TC would intensify in a balanced framework with thermal wind balance and moist slantwise neutrality in the eyewall region. Recent studies (Van Sang et al. 2008; Montgomery and Smith 2014; Persing et al. 2013) have proposed an intensification mechanism in which the TC vorticity is enhanced through the merger of vorticity-rich convective cells generated around the core. Smith et al. (2009) argued the importance of the boundary layer for the spinup of TC. An enhancement of angular momentum can occur in the boundary layer because of the strong inward transport, whereas the traditional theories of TC 
intensification have assumed that the angular momentum is transported above the boundary layer.

Acceleration of tangential velocity has been examined by a balanced framework in which a TC satisfies the gradient wind and hydrostatic balance (Schubert and Hack 1982; Shapiro and Willoughby 1982; Nolan et al. 2007; Pendergrass and Willoughby 2009; Willoughby 2009; Vigh and Schubert 2009). Nolan and Grasso (2003) and Nolan et al. (2007) investigated the dynamical response of a rotating fluid system to the axisymmetric and asymmetric components of diabatic heating. They found that the axisymmetric component plays a primary role in accelerating the azimuthally averaged tangential velocity, whereas asymmetric heating has a small effect. Pendergrass and Willoughby (2009) demonstrated that diabatic heating inside the radius of maximum tangential velocity (RMW) enhances the tangential velocity much more effectively than that outside the RMW.

Because of its importance, RI has been studied extensively in recent years (Reasor et al. 2009; Rogers 2010; Guimond et al. 2010; Barnes and Fuentes 2010; Chen et al. 2011; Reasor and Eastin 2012; Zhang and Chen 2012; Miyamoto and Takemi 2013, hereafter MT13; Chen and Zhang 2013; Rogers et al. 2013, 2015). Rogers (2010) conducted a numerical simulation of Hurricane Dennis (2005), and found that the RI of Dennis was triggered by a sudden increase in upward mass flux at $1.5-\mathrm{km}$ altitude, which resulted from both the enhanced secondary circulation and local buoyant bursts. Guimond et al. (2010) analyzed the observational data for Hurricane Dennis (2005) obtained from airborne Doppler radar and satellite measurements and found that convective downdrafts increased the temperature in the eye and inward motion toward the eye during the initial development of the hurricane. Barnes and Fuentes (2010) examined data obtained from integrated aircraft reconnaissance missions and found that the difference in the equivalent potential temperatures between the eye and eyewall increases prior to RI and suddenly decreases after the onset of RI. A composite analysis of the reflectivity of observed TCs (Harnos and Nesbitt 2011; Kieper and Jiang 2012; Jiang 2012) indicated that TCs tend to have an eyewall during RI under a moderate shear. Rogers et al. (2015) constructed composites of convective bursts in both the early and the latter stages of the RI of Hurricane Earl (2010). They found that the convective bursts were widely distributed over multiple radii in the early stages of RI, with the bursts concentrated inside the RMW. They discussed the potential role of boundary layer convergence in determining the radial location of convective bursts. Although these studies have suggested that the thermodynamic and kinematic properties of the TC core play an important role in initiating RI, when the TC vortex enters the RI phase and which physical processes trigger RI remain unclear.

MT13 conducted idealized numerical experiments to investigate the mechanism for the transition to RI, defined as the period in which the intensification rate rapidly increases. They found that, as a TC core becomes inertially stable through vortex axisymmetrization, the equivalent potential temperature in the boundary layer increases inside the RMW where an eyewall subsequently forms. The authors proposed that the enhancement of equivalent potential temperature results from the increased duration time of fluid parcels in the core as a result of enhanced inertial stability. The enhanced equivalent potential temperature in the boundary layer makes the core region convectively unstable (i.e., favorable for the formation of strong convection). An eyewall then forms by consuming the enhanced convective available potential energy (CAPE) in the core, and RI starts. However, which process triggers the consumption of the enhanced CAPE is unclear.

Therefore, the purpose of this study was to identify the triggering mechanism for RI. We used the results of both idealized numerical experiments and a realistic simulation obtained from a three-dimensional full-physics model. Our three-dimensional experiment was identical to the control run of MT13, and we used the simulation results of Nolan et al. (2013, hereafter N13) to verify our results. Section 2 describes the experimental settings and the numerical model. Section 3 presents the results of the idealized numerical experiment and the simulation, and section 4 proposes a triggering mechanism based on our results. Section 5 presents our conclusions.

\section{Numerical model and experimental design}

\section{a. Experimental setting of $M T 13$}

We used the results of the MT13 idealized numerical experiment for the main analyses and used the realistic simulation conducted by N13 to verify our findings. Both results were obtained using a compressible, nonhydrostatic model, the Advanced Research version of the Weather Research and Forecasting (WRF) Model (ARW; Skamarock et al. 2008). The WRF Model solves tendencies for three-dimensional momentum, perturbation geopotential, perturbation potential temperature, perturbation surface pressure of dry air, and mixing ratios of water content.

The experimental setting used in MT13 was simplified to remove external forcings, such as the vertical shear of horizontal wind. Microphysical processes were represented by the warm-rain parameterization that solves tendencies in the mixing ratios of cloud water and 
rainwater (Kessler 1969). For simplicity, the effects of radiation were not included in this experiment. Subgrid turbulence was solved using Smagorinsky parameterization (Smagorinsky 1963; Lilly 1962). Surface fluxes were estimated using bulk formulas. Exchange coefficients for momentum and thermodynamic quantities were formulated based on recent experimental and observational studies (e.g., Donelan et al. 2004).

Two numerical domains were prepared: an outer numerical domain that covered $3000 \mathrm{~km} \times 3000 \mathrm{~km}$ with 6-km horizontal grid spacing and an inner domain which covered $600 \mathrm{~km} \times 600 \mathrm{~km}$ with 2-km spacing. Both domains used 44 vertical stretched levels up to $50 \mathrm{hPa}$. The averaged grid spacings below $1.0 \mathrm{~km}$ and between $z=1.0$ and $15.0 \mathrm{~km}$ were 151.44 and $499.86 \mathrm{~m}$, respectively. At the top of the domain, a sponge layer with a depth of $2846 \mathrm{~m}$ was inserted to prevent gravity waves from reflecting at the top boundary. The domains were interacted at every time step (6s) of the outer domain (i.e., two-way nesting).

The initial field in the numerical experiment was horizontally homogeneous with an axisymmetric weak vortex. The vertical profiles of temperature and water vapor mixing ratio were obtained from the tropical mean soundings (Jordan 1958). An axisymmetric vortex, as described by Rotunno and Emanuel (1987), was inserted at the center of the domain. Figure 1 depicts the radius-height cross section of initial tangential velocity. The maximum tangential velocity was $12 \mathrm{~m} \mathrm{~s}^{-1}$ at a radius of $80 \mathrm{~km}$. During the integration, the Coriolis parameter $f$ was fixed at $1.5 \times 10^{-5} \mathrm{~s}^{-1}$. No orthogonal fluxes were permitted at the lateral and top boundaries. The lower boundary was regarded as the ocean, with a constant surface temperature of $300 \mathrm{~K}$ during the integration. The integration period was $200 \mathrm{~h}$.

\section{b. Experimental setting of $N 13$}

N13 was undertaken as a "nature run" for a single TC with a high spatial and temporal resolution. The TC was originally simulated in a global nature run using the forecast model of the European Centre for MediumRange Weather Forecasts (ECMWF) with T511 spectral resolution and 91 vertical levels. The TC was generated in the central Atlantic, moved northwestward, and decayed in the northern Atlantic. The results of the global nature run were used as the initial and boundary conditions of the simulation. N13 revealed that the TC sustained tropical storm strength for several days and underwent RI during its lifetime.

N13 involved four numerical domains in which the domains were interactive. The outermost domain covered the tropical North Atlantic and had $240 \times 160$ grids with $27-\mathrm{km}$ grid spacing. The first nested domain had $120 \times 120$ grids with 9 -km spacing, the second had

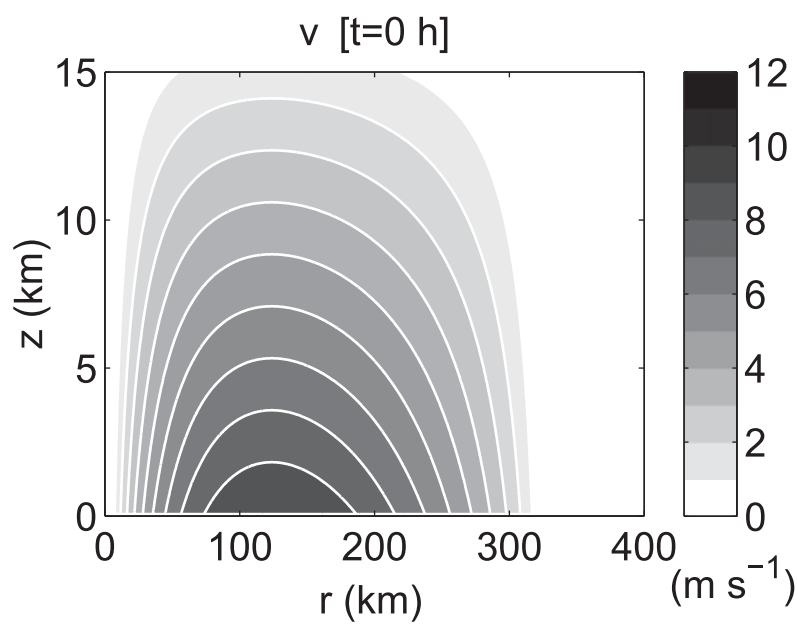

FIG. 1. Radius-height cross section of tangential velocity at the initial time of the idealized numerical experiment.

$240 \times 240$ grids with $3-\mathrm{km}$ spacing, and the third had $480 \times 480$ grids with $1-\mathrm{km}$ spacing. The simulation was conducted using a vortex-following method by searching the center of vortex, so the domains (except the outermost domain) move spatially with time. The number of grids in the vertical direction was 61 for all domains.

The following parameterizations were used for the physical processes. The microphysics processes were solved using a 6-class double-moment scheme (Lim and Hong 2010). The RRTMG schemes (Iacono et al. 2008) were used for both longwave and shortwave radiation. The Yonsei University planetary boundary layer scheme (Noh et al. 2003; Hong et al. 2006) was implemented for surface fluxes and turbulent mixing in the boundary layer. The exchange coefficients for the surface fluxes of momentum, heat and moisture were calculated (Davis et al. 2008; Dudhia et al. 2008), and the ocean cooling processes were solved using the mixedlayer model in ARW. The Kain-Fritsch convective parameterization (Kain and Fritsch 1990; Kain 2004) was implemented for the outermost and first nested domain. For more details regarding the experimental settings and simulated TC, see N13.

\section{Results}

\section{a. Overview of the simulated TC}

Figure 2a presents a time series of the maximum horizontal velocity at a height of $1 \mathrm{~km}$ and the axisymmetricity $\gamma_{\mathrm{PV}}$, which is defined by MT13 and represents the degree of the axisymmetric structure of a vortex using Ertel's potential vorticity (PV). Figures $2 b$ and $2 \mathrm{c}$ show a time series of the RMW and intensification rate. The RMW temporally decreases, 

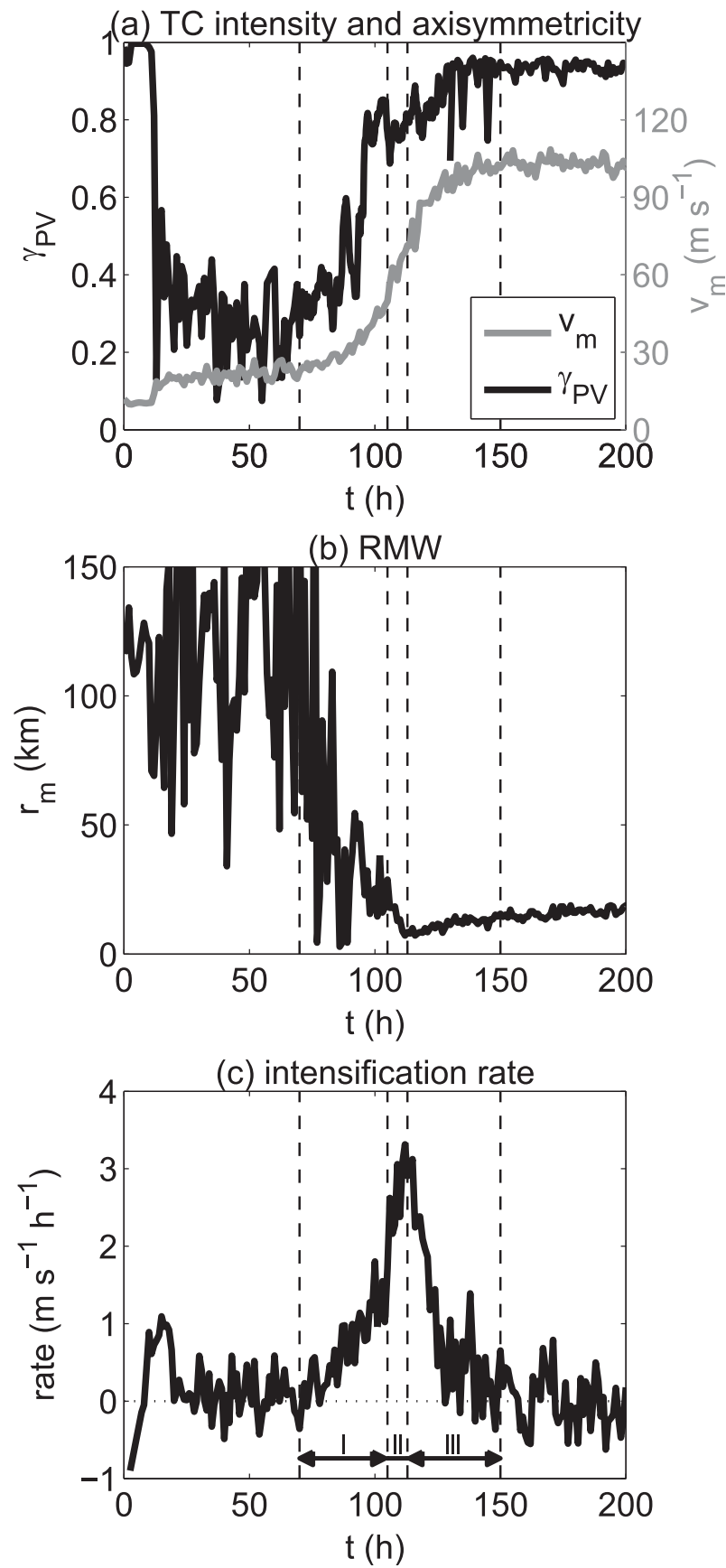

FIG. 2. Time series of (a) maximum wind speed (gray line) and the axisymmetricity (black line) evaluated by Ertel's PV, (b) RMW, and (c) intensification rate. The periods labeled I, II, and III refer to the subphases of the intensification phase, as determined by the intensification rate.

reaching the minimum $(\sim 10 \mathrm{~km})$ at $t=105 \mathrm{~h}$, and it subsequently retains that value. The intensification rate is initially very small before $t=70 \mathrm{~h}$, gradually increases, and then rapidly increases after $t=105 \mathrm{~h}$. This indicates that the simulated TC intensified from $t=70$ to $150 \mathrm{~h}$, and then sustained its maximum intensity, with small fluctuations, until the end of the experiment. We defined the former and latter periods as the intensification phase and the quasi-steady phase, respectively. The intensification phase was further divided into three subphases according to the rate of intensification: a slowly intensifying phase (phase I, $t=70-105 \mathrm{~h}$ ), a rapidly intensifying phase (phase II, $t=105-113 \mathrm{~h}$ ), and a phase of adjustment to the quasi-steady state (phase III, $t=113$ $150 \mathrm{~h}$ ). Phase II was defined as the RI. For the purposes of this study, we focused on the later period of phase I to examine the processes that trigger RI.

Figure 2a shows that $\gamma_{\mathrm{PV}}$ was initially 1 , because an axisymmetric vortex was inserted at $t=0$. After tailing off to about 0.3 , it increased again to approximately 0.8 around $t=93 \mathrm{~h}$ and thereafter maintained a large value. The rapid increase in $\gamma_{\mathrm{PV}}$ at $t=93 \mathrm{~h}$ in Fig. 2 indicates that the TC became almost axisymmetric $12 \mathrm{~h}$ before RI $(t=105 \mathrm{~h})$. It should be noted that the small drop in the axisymmetricity around $t=2-3 \mathrm{~h}$ resulted from a slight difference in the centers of the surface pressure and velocity fields.

\section{b. Structure transformation at the onset of RI}

To highlight the changes in structure before and after the onset of RI $(t=105 \mathrm{~h})$, Fig. 3 displays horizontal cross sections of the liquid water mixing ratio that were vertically averaged between $z=1.5$ and $12.0 \mathrm{~km}$. Before the onset of RI, a number of convective cells were present inside the RMW. In contrast, a ring-shaped peak in the water content appeared immediately inside the RMW after $t=105 \mathrm{~h}$.

Figure 4 depicts radius-height cross sections of the temporally averaged tangential velocity from $t=100$ to $105 \mathrm{~h}$ (Fig. 4a) and from $t=105$ to $110 \mathrm{~h}$ (Fig. 4b). It can be seen that the flow structure changed remarkably between these two periods. The peak value significantly increased after $t=105 \mathrm{~h}$, and its radius shrank. The tangential velocity increased in the upper troposphere. The radius-height composites for the temporally averaged radial flow and mixing ratio of total condensed water are shown in Fig. 5. A secondary circulation was present during both periods: a strong inflow and outflow existed below the $1-\mathrm{km}$ level and above $14 \mathrm{~km}$, respectively. Whereas the secondary circulation intensified after $t=105 \mathrm{~h}$, the overall flow structure did not differ significantly between the two periods. A clear difference appeared in the diabatic heating. After the onset of RI $(t=105 \mathrm{~h})$, a high diabatic heating region appeared around $t=10 \mathrm{~km}$, corresponding with the RMW at this time.

To understand the process of intensification before and during the RI, we conducted a budget analysis using 

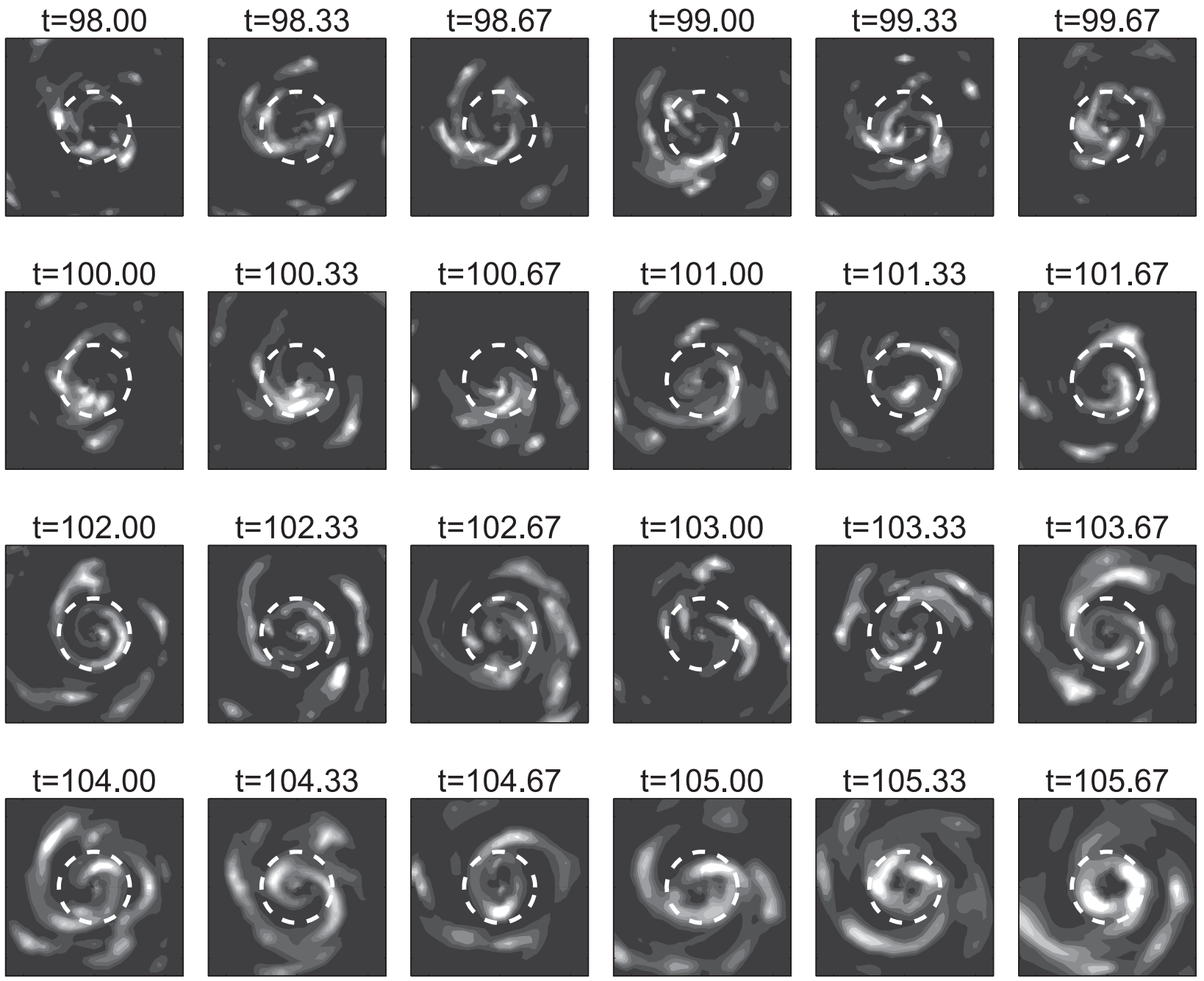

FIG. 3. Horizontal cross sections of the total water content, vertically averaged from $z=1.5$ to $12.0 \mathrm{~km}$ at every $20 \mathrm{~min}$ after $t=98 \mathrm{~h}$. The dashed circle indicates the RMW. The horizontal axes are normalized by the RMW, and each panel covers an area inside 2.5 times the RMW. The maximum value shown by the white color is $10^{-3} \mathrm{~kg} \mathrm{~kg}^{-1}$.

the tangential momentum equation in Persing et al. (2013). Figure 6 shows the radius-height cross section of the budget terms of the equation before and after the onset of RI. It can be seen that the tangential velocity is accelerated mainly by the mean advection (specifically, the radial advection and centrifugal terms). These results indicate that the simulated TC intensified through the inward transport of absolute angular momentum by the symmetric flow.

Figure 7 displays a time-height cross section of the area-averaged diabatic heating rates inside the RMW, and in the region from RMW $-\Delta r_{\text {ew }}$ to the RMW, where $\Delta r_{\text {ew }}(=6 \mathrm{~km})$ was approximately the width of the strong convective region (i.e., eyewall) when it formed at $t=105 \mathrm{~h}$. The diabatic heating rate clearly remained large inside the RMW after $t=100 \mathrm{~h}$. In contrast, the average rate in the 6-km distance from the RMW was small before $t=104 \mathrm{~h}$ but became larger than the average inside the RMW. Thus, the diabatic heating was concentrated around the RMW after $t=104 \mathrm{~h}$, whereas the heating has a nonzero value inside the RMW from $t=100 \mathrm{~h}$ onward.

The results introduced here, as well as those shown in MT13, indicate that RI in the simulated TC started around the time of eyewall formation. Note that eyewall is defined here as a strong convective region around the RMW, in which the axisymmetric component of diabatic heating or water content is large. An eyewall may form by either dynamic forcing, such as low-level convergence, or thermodynamic forcing. Once the convergence in the boundary layer suddenly increases in a high-CAPE region (MT13), strong 
(a) $\vee[t=100-105 \mathrm{~h}]$

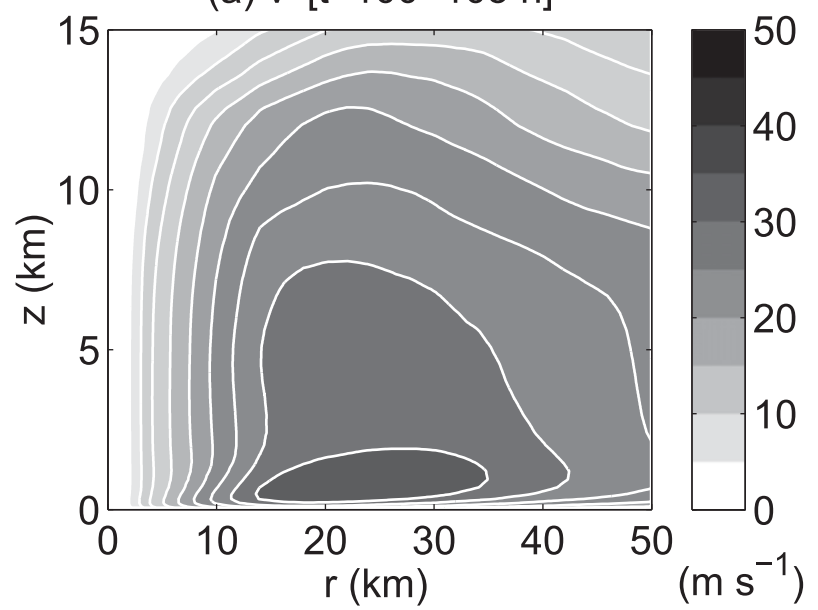

(b) $\vee[t=105-110 \mathrm{~h}]$

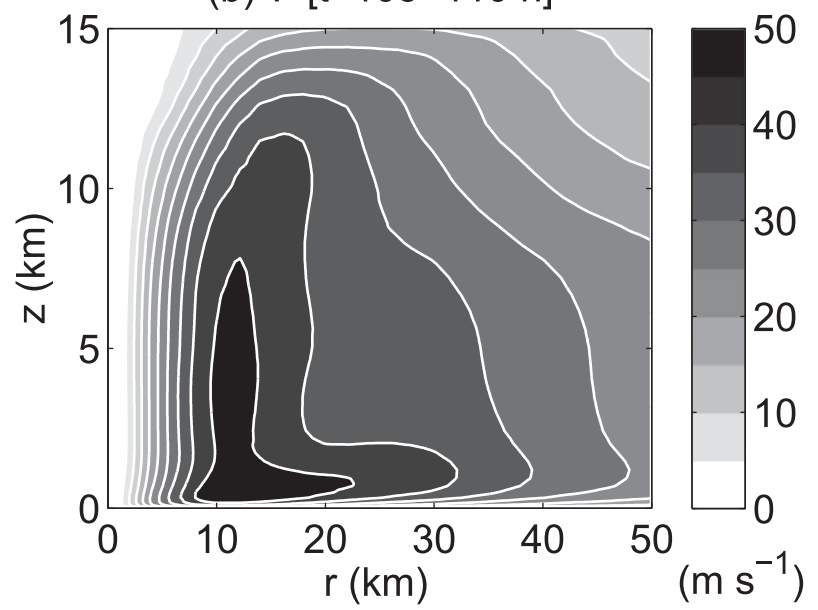

FIG. 4. Radius-height cross sections of composites of tangential velocity (a) before and (b) after the onset of RI. The contour interval is $5 \mathrm{~m} \mathrm{~s}^{-1}$. The averaging periods are $5 \mathrm{~h}$ before and after the onset of RI.

convection will be initiated using the CAPE and the feedback process starts. Alternatively, an eyewall may develop from a single convective cell (or multiple cells) that does not necessarily have a circular shape when it is generated, by consuming large amounts of CAPE. If a convective cell moves into the high-CAPE region, it appears to intensify and to enhance the secondary circulation.

\section{c. Trigger of RI}

To determine which process plays the key role in forming the eyewall and contributes most to triggering the RI, we examined a time series of the spatially averaged low-level convergence and diabatic heating (Fig. 8). Both were averaged in the azimuthal direction and in a $10-\mathrm{km}$ radius centered at the RMW. The
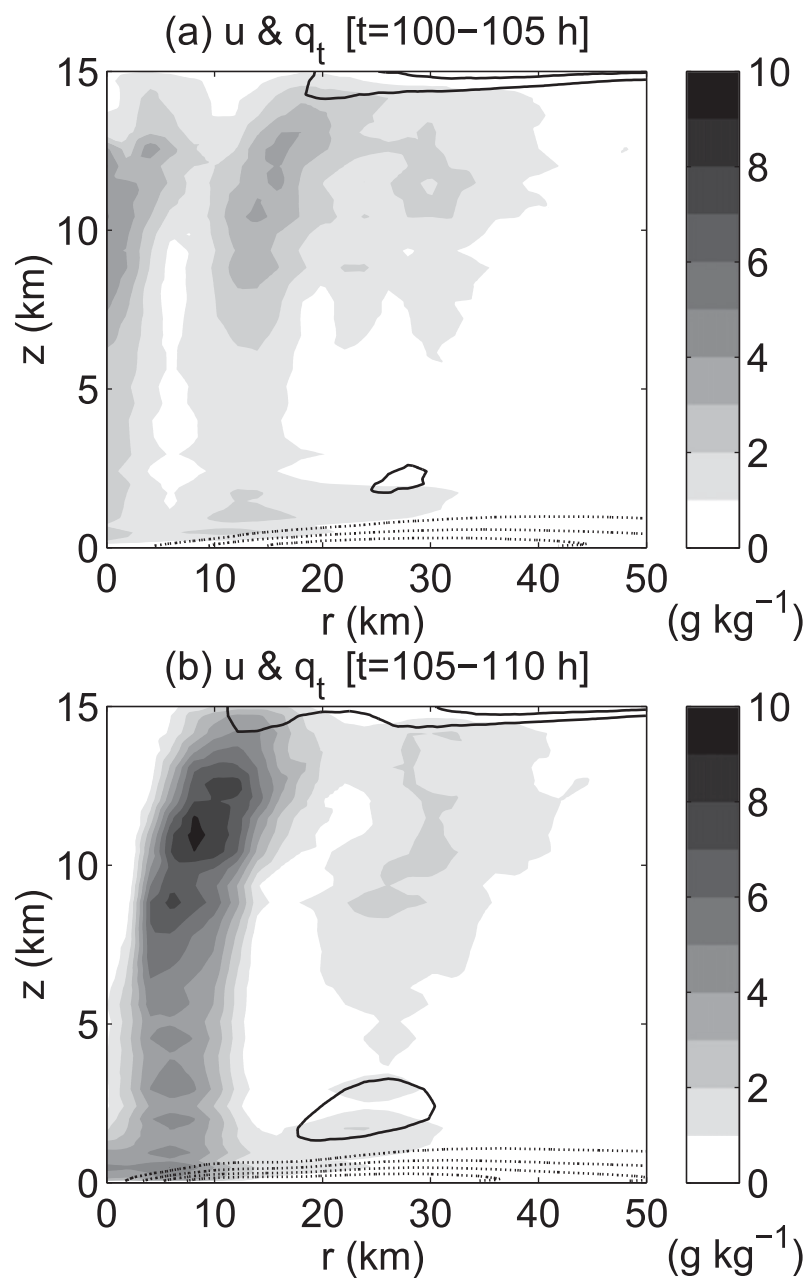

FIG. 5. As in Fig. 4, but for radial velocity (contour) and the mixing ratio of total condensed water (shaded). The contour interval for positive values (solid) is $2 \mathrm{~m} \mathrm{~s}^{-1}$, and the interval for negative values (dashed) is $4 \mathrm{~m} \mathrm{~s}^{-1}$.

horizontal mass convergence was further averaged in the lowest $0.5-\mathrm{km}$ layer, and the diabatic heating was averaged from $z=1.5$ to $12.0 \mathrm{~km}$. Both quantities increased over the period studied, especially after the onset of RI ( $t=105 \mathrm{~h})$, and continued to increase during RI. The rapid increase after $t=105 \mathrm{~h}$ and the similar behavior of both quantities suggest that the positivefeedback process described in the introduction operated during the RI between the secondary circulation and the diabatic heating in the eyewall.

The close-up view around the onset of RI reveals that the diabatic heating began to increase $30 \mathrm{~min}$ earlier than the low-level convergence. Although the time difference was short (30 $\mathrm{min})$, there were three sets of temporal data in this period. Therefore, these results indicate that the key process for initiating RI in the simulated TC is the enhancement of diabatic heating around the RMW. 

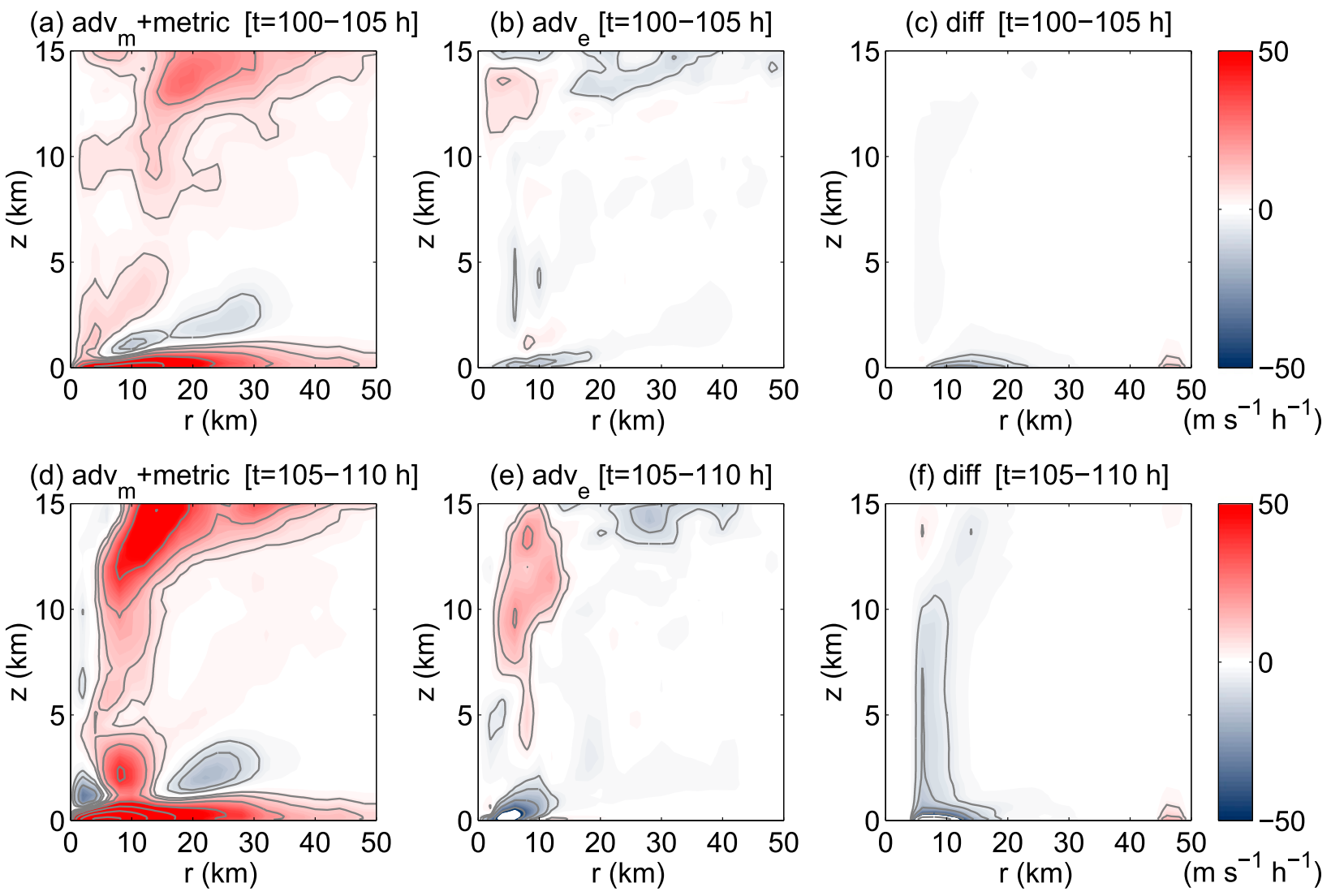

FIG. 6. Radius-height composites for the terms of the tangential velocity equation: (a),(d) advection of the mean component and metric terms, (b),(e) advection of eddy terms, and (c),(f) diffusion terms. Composites are averaged (top) from $t=100$ to $105 \mathrm{~h}$ and (bottom) from $t=105$ to $110 \mathrm{~h}$. The contour levels are $5,10,20,40,80,160$, and $320 \mathrm{~m} \mathrm{~s}^{-1} \mathrm{~h}^{-1}$. The positive (negative) values are indicated by solid (dashed) lines.

\section{d. Convective cell developed into the eyewall}

The structural changes in the cloud fields were examined especially inside the RMW around the onset of RI. Figure 9 presents the radius-azimuth cross sections of the vertically averaged liquid water mixing ratio every $20 \mathrm{~min}$ before and after the onset of RI. A number of cloud cells were generated inside the RMW before the onset of RI $(t=105 \mathrm{~h})$, and a large-watercontent region appeared in almost all azimuths after $t=$ $105 \mathrm{~h}$. These findings are consistent with those shown in Fig. 3, and the large-water-content region can be regarded as the eyewall. The eyewall cloud consisted of two or more peaks of water content, or convective cells. The cell with a strong peak around the azimuth of $0.5 \pi$ at $t=105 \mathrm{~h}$ (marked by the dashed circle) could be traced backward.

The cloud cell appeared around the RMW at $t=$ $103.67 \mathrm{~h}$, and moved tangentially at approximately $15 \mathrm{~m} \mathrm{~s}^{-1}$. During this movement, the cell expanded in the tangential direction and ultimately developed into almost all azimuths around $t=105 \mathrm{~h}$. It should be noted that eyewall was defined above a strong convective region around the RMW in which the axisymmetric component of diabatic heating or water content was large. The eyewall or large axisymmetric component of the water content in the TC consisted of two convective cells.

This result raises the question of why a particular cell develops into an eyewall. Figures 3 and 9 show that a number of convective cells were present inside the RMW after the simulated TC became nearly axisymmetric $(t=93 \mathrm{~h})$. Although the core region had a large CAPE during this period (cf. Fig. 12 of MT13), only one particular cell that was generated approximately $10 \mathrm{~h}$ after the CAPE became large developed into the eyewall. To determine why this convective cell behaved differently from the others, we objectively tracked all the convective cells that appeared inside the RMW after $t=93 \mathrm{~h}$.

We used the methodology developed by Miyamoto et al. $(2013,2015)$ to detect convective cells, but we 

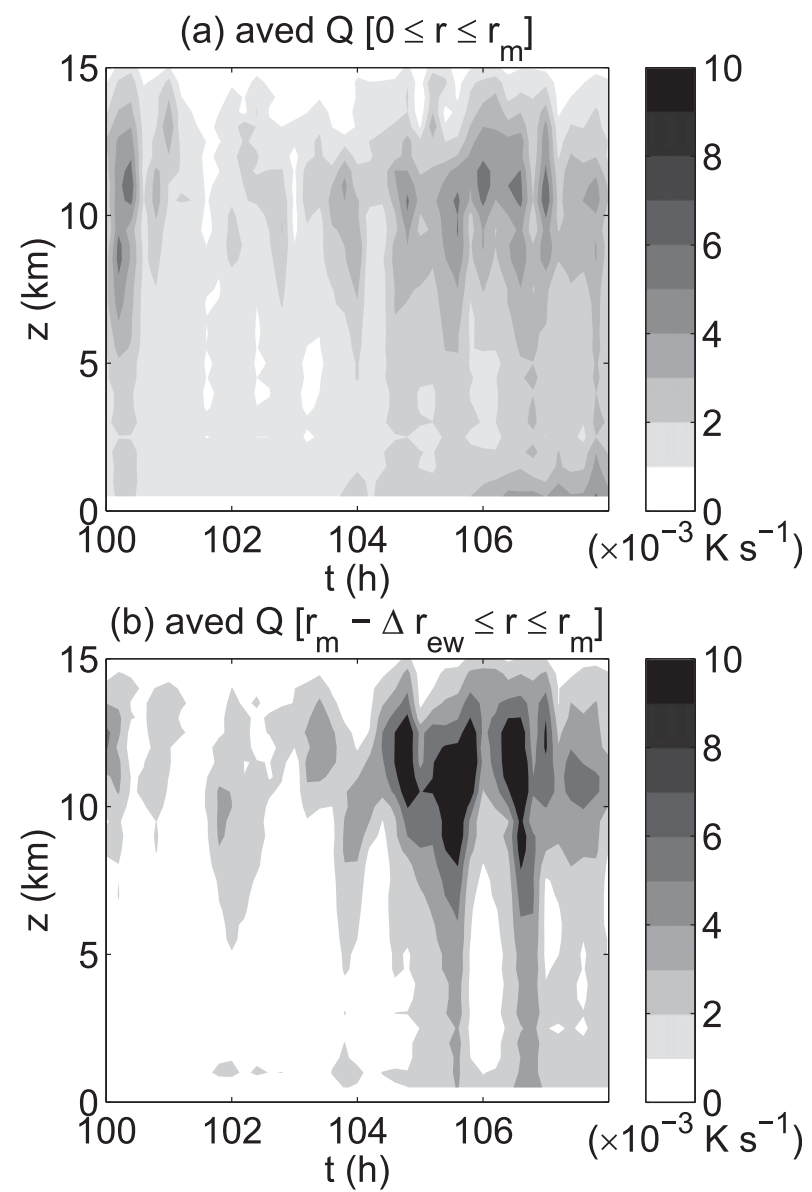

FIG. 7. Time-height cross sections for area-averaged diabatic heating rates (a) from the center to the RMW and (b) from RMW $-\Delta r_{\text {ew }}$ to the RMW, where $\Delta r_{\text {ew }}$ is the eyewall width of the simulated TC at $t=105 \mathrm{~h}(=6 \mathrm{~km})$.

used the vertically averaged water density to diagnose convective grids rather than the ISCCP table (Rossow and Schiffer 1999). First, we determined the convective grids where the sum of cloud and rainwater mixing ratios averaged from 1.5 to $12.0 \mathrm{~km}$ was greater than $2 \mathrm{~g} \mathrm{~kg}^{-1}$. Second, we detected convective core grids in which the vertically averaged vertical velocity was larger than the neighboring eight grids. For this analysis, the data, which were outputted every $10 \mathrm{~min}$, were linearly interpolated to a 5-min interval. This twostep calculation was conducted inside the RMW for every output time. The core grids that were detected were then advected by the vertically averaged horizontal velocity at a certain output interval (e.g., from $t=t_{1}$ to $t_{2}=t_{1}+\Delta t_{o}$, where $\Delta t_{o}$ is the output interval, which was $5 \mathrm{~min}$ in this case). The horizontal velocity was averaged between $z=1.5$ and $12.0 \mathrm{~km}$. To diagnose whether the advected core grids from $t=t_{1}$ to $t_{2}$ had survived at the next output time $\left(t=t_{2}\right)$, we

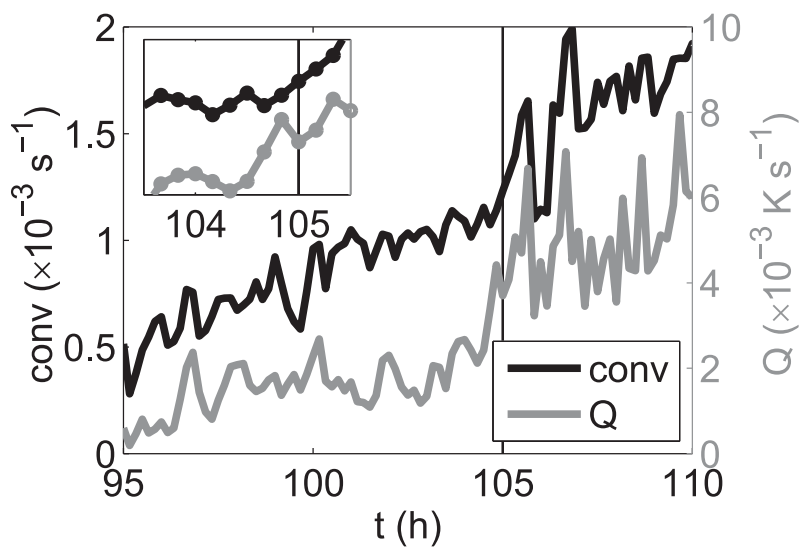

FIG. 8. Time series of the diabatic heating rate (gray line; right axis) and horizontal convergence averaged in the boundary layer (black line; left axis). Both are averaged in the tangential direction within a 5-km radial distance from the RMW. The boundary layer convergence is also averaged at the lowest $500 \mathrm{~m}$, whereas the diabatic heating is averaged from $z=1.5$ to $12.0 \mathrm{~km}$. The vertical thin line indicates the time at which the simulated TC begins RI. The small window is a close-up view from $t=103$ to $106 \mathrm{~h}$ : the lines are identical to those in the main panel.

searched for core grids detected at $t=t_{2}$ around the advected locations. If a core grid appeared within $6 \mathrm{~km}$ (three grids) from the advected location, these two cores were considered to be identical. Because the output interval $\Delta t_{o}$ in this case was $5 \mathrm{~min}$, the velocity that advected the convection for a $6-\mathrm{km}$ distance in $300 \mathrm{~s}$ was approximately $20 \mathrm{~m} \mathrm{~s}^{-1}$. The advecting speed appeared to be determined by horizontal velocities in the middle troposphere, so the upper limit of $20 \mathrm{~m} \mathrm{~s}^{-1}$ may be reasonable. We analyzed core grids that were maintained for at least $20 \mathrm{~min}$.

Figure 10 presents the tracks of all the detected convective cells between $t=93$ and $105 \mathrm{~h}$. A total of 44 cells (i.e., 44 convective core grids) were detected inside the RMW in this period. These cells moved in a cyclonic fashion, with durations of a few tens of minutes to an hour. The convective cell that developed into the eyewall also moved tangentially, as seen in Fig. 9. The lifetime of this cell was the longest of all the detected cells: it was sustained for approximately $1.5 \mathrm{~h}$ before it developed into the eyewall. This finding is also consistent with Fig. 9, suggesting that the tracking scheme works reasonably well.

Figure 11 depicts the radius-height composites of the relative vertical vorticity and radial profiles of the frequency of convective cells during the transition phase $(t=93-105 \mathrm{~h})$ and during the RI $(t=105-113 \mathrm{~h})$. It is clear that the convective cells are concentrated inside the RMW after the onset of RI, whereas the convection is widely distributed before the onset of RI. This is 

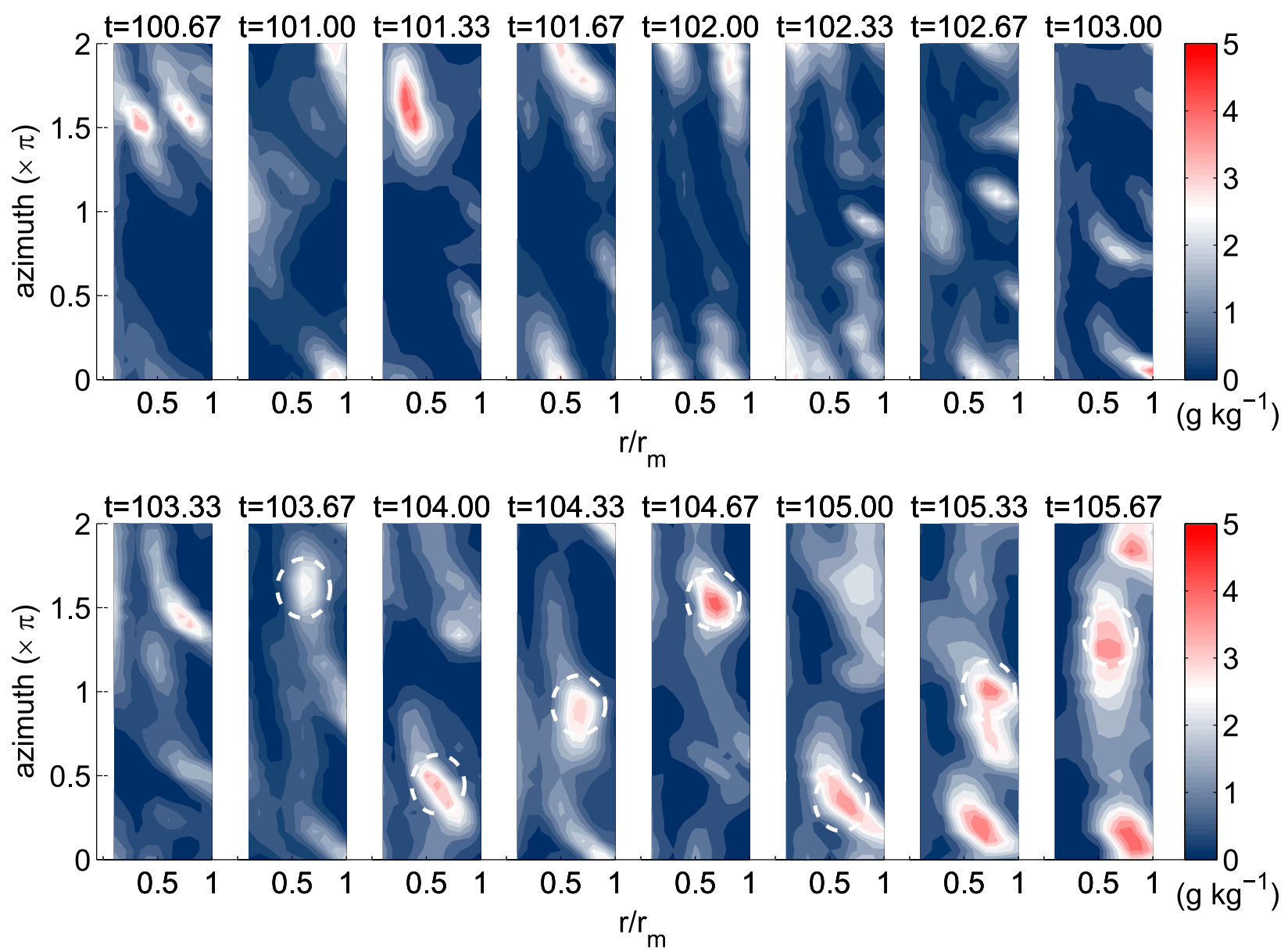

FIG. 9. Radius-azimuth cross sections for the vertically averaged water content determined every 20 min. The radius is normalized by the RMW. The azimuth starts from east and moves in a counterclockwise sense. The water content is averaged from $z=1.5$ to $12.0 \mathrm{~km}$. The convective cell discussed in the text is marked by the dashed circle.

consistent with the previous observational studies (Rogers et al. 2013, 2015).

Figure 12 presents the times series of $\gamma_{\mathrm{PV}}$, the convergence of axisymmetric flow, and the convergence estimated by both axisymmetric and asymmetric components (i.e., local convergence). The first two quantities were estimated at the radius where the cell existed, whereas the local convergence was calculated at the grid in which the cell appeared. The axisymmetricity was averaged from $z=1.5$ to $12.0 \mathrm{~km}$, whereas the convergences were averaged in the lowest $1 \mathrm{~km}$. Figure 12a shows that over their lifetime, almost all cells had a large $\gamma_{\mathrm{PV}}$ during the calculation period. The axisymmetricity of the cell that subsequently developed into the eyewall (gray lines) was not significantly different from those of the other cells. In contrast, the convergence of axisymmetric flow in that cell was remarkably large compared with the others (Fig. 12b). The convergence of total flow of the cell was also large, but the difference from the other cells was not as significant (Fig. 12c). We also investigated other parameters, such as the vertically integrated water content or vertically averaged vertical velocity, but none of these differed remarkably (data not shown). In conclusion, the lowlevel convergence due to axisymmetric flow was significantly larger in the developing cell than in the other cells.

It should be noted that, although this study showed that the axisymmetric component of convective heating played a key role in triggering the RI, the amplification of the axisymmetric component resulted from the development of a convective cell. In this regard, these results are consistent with many previous studies (Reasor et al. 2009; Molinari and Vollaro 2010; Guimond et al. 2010; Stevenson et al. 2014; Rogers et al. 2015) that have emphasized the importance of convective bursts for driving the RI. 


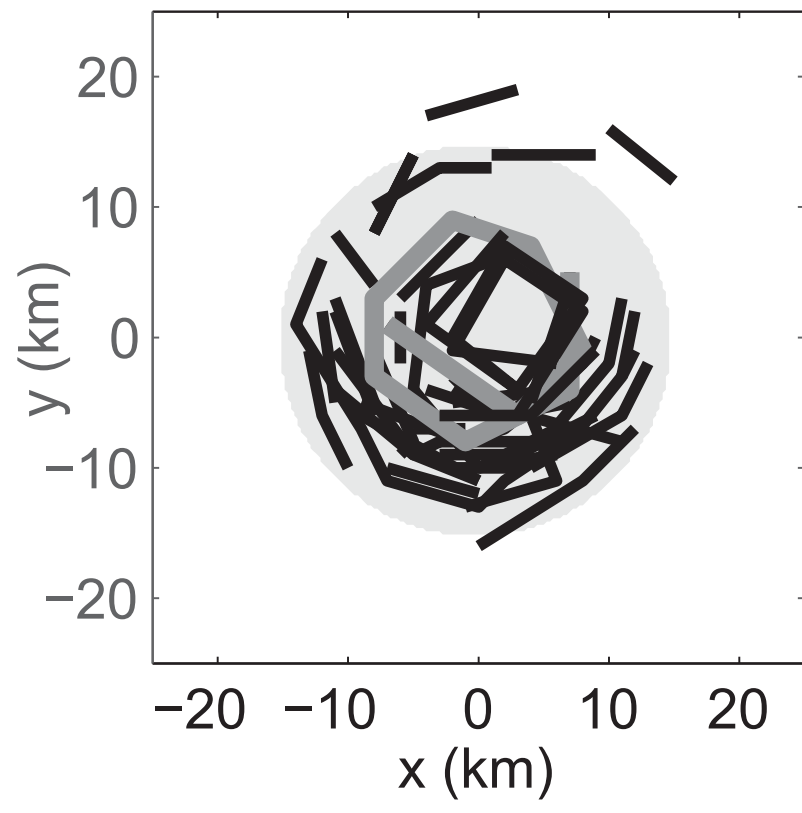

FIG. 10. Tracks of the detected convective cells that appear inside the RMW from when the TC becomes almost axisymmetric $(t=93 \mathrm{~h})$ to the onset of RI $(t=105 \mathrm{~h})$. The gray line indicates the track of the cell that developed. The RMW that is temporally averaged during the analyzed period is the outer edge of the light gray area.

\section{e. Results of N13}

To verify the results obtained from the idealized experiment discussed above, we conducted the same analyses for the results of N13. Figure 13 presents a time series of TC intensity and axisymmetricity for $\mathrm{PV}$. The axisymmetricity was calculated inside $r=$ $100 \mathrm{~km}$ and between $z=1.5$ and $12.0 \mathrm{~km}$. The figure clearly shows that the simulated TC in N13 undergoes $\mathrm{RI}$ after $t=56 \mathrm{~h}$. The axisymmetricity starts increasing at $t=40 \mathrm{~h}$ and achieves a large value around $t=44 \mathrm{~h}$, which is $11 \mathrm{~h}$ before the onset of RI. Thereafter, it maintains a large value. This result is consistent with the development of horizontal TC structure as demonstrated by N13 and is also consistent with the results obtained during the control run of MT13 (cf. Fig. 2).

Figure 14 presents the radius-time cross section of the averaged CAPE, diabatic heating rate, and the RMW of the TC simulated by N13. The CAPE was estimated by considering an air parcel averaged in the lowest 500-m layer. The heating rate was vertically averaged from $z=1.5$ to $12.0 \mathrm{~km}$. Both quantities were averaged in the tangential direction. The figure shows that the CAPE increases inside the RMW after the TC becomes axisymmetric $(t=44 \mathrm{~h})$, and it disappears once RI begins $(t=56 \mathrm{~h})$. A large diabatic heating region appears
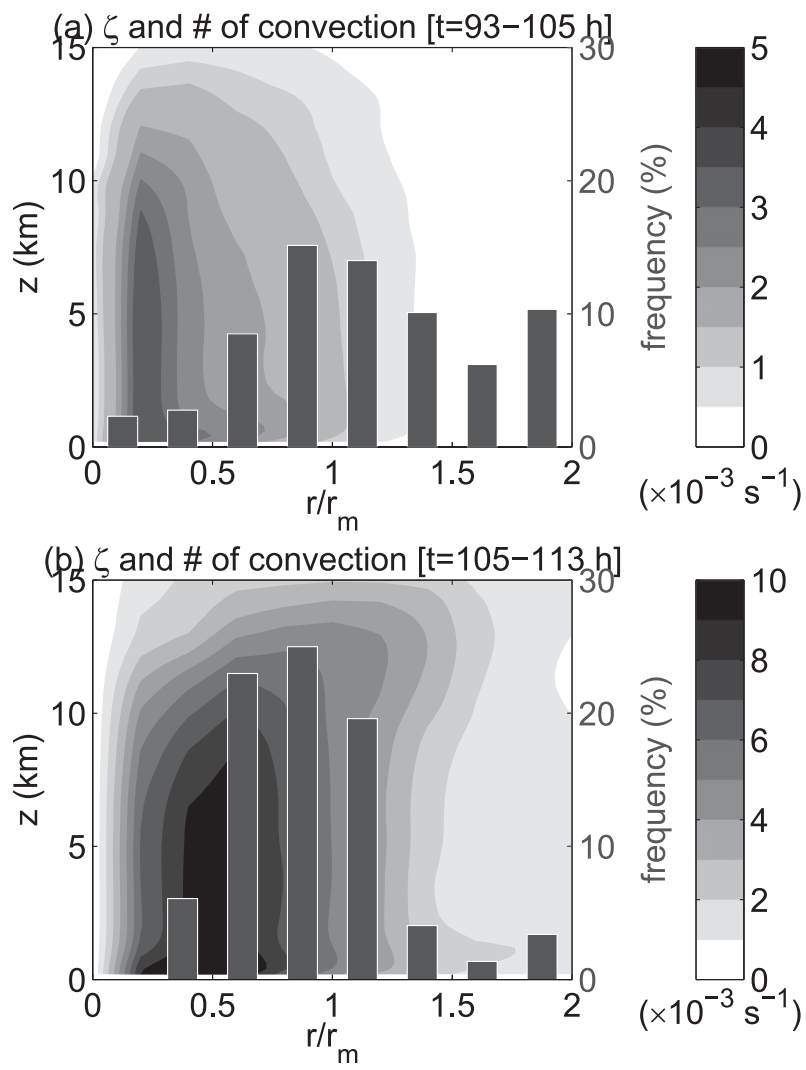

FIG. 11. Radial profile of the number of convective cells embedded in the radius-height composite for vertical relative vorticity (a) during the transition phase $(t=93-105 \mathrm{~h})$ and (b) during the RI $(t=105-113 \mathrm{~h})$.

around the RMW immediately before the onset of RI, and it persists afterward. This region can be regarded as the eyewall. These results strongly suggest that the increased CAPE is used to form the eyewall. N13 observed the appearance of an eyewall after the simulated TC began RI (cf. Figs. 5-7 and 9 in N13). Unlike the current idealized experiment, the simulation settings in N13 were much more realistic with nonzero vertical shears and temporally varying sea surface temperature and Coriolis parameter. Nevertheless, the results obtained from the realistic simulation of N13 were consistent with those for the idealized experiment of MT13.

Figure 15 presents a time series of the averaged boundary layer convergence and diabatic heating. Both of the averaged regions are the same as those shown in Fig. 8. Although both parameters basically increased throughout the analysis period, the parameters were extremely large after the onset of RI. The diabatic heating rate started increasing slightly earlier than the boundary layer convergence, which is also consistent with the results presented here (Fig. 8). 
(a) axisymmetricity PV
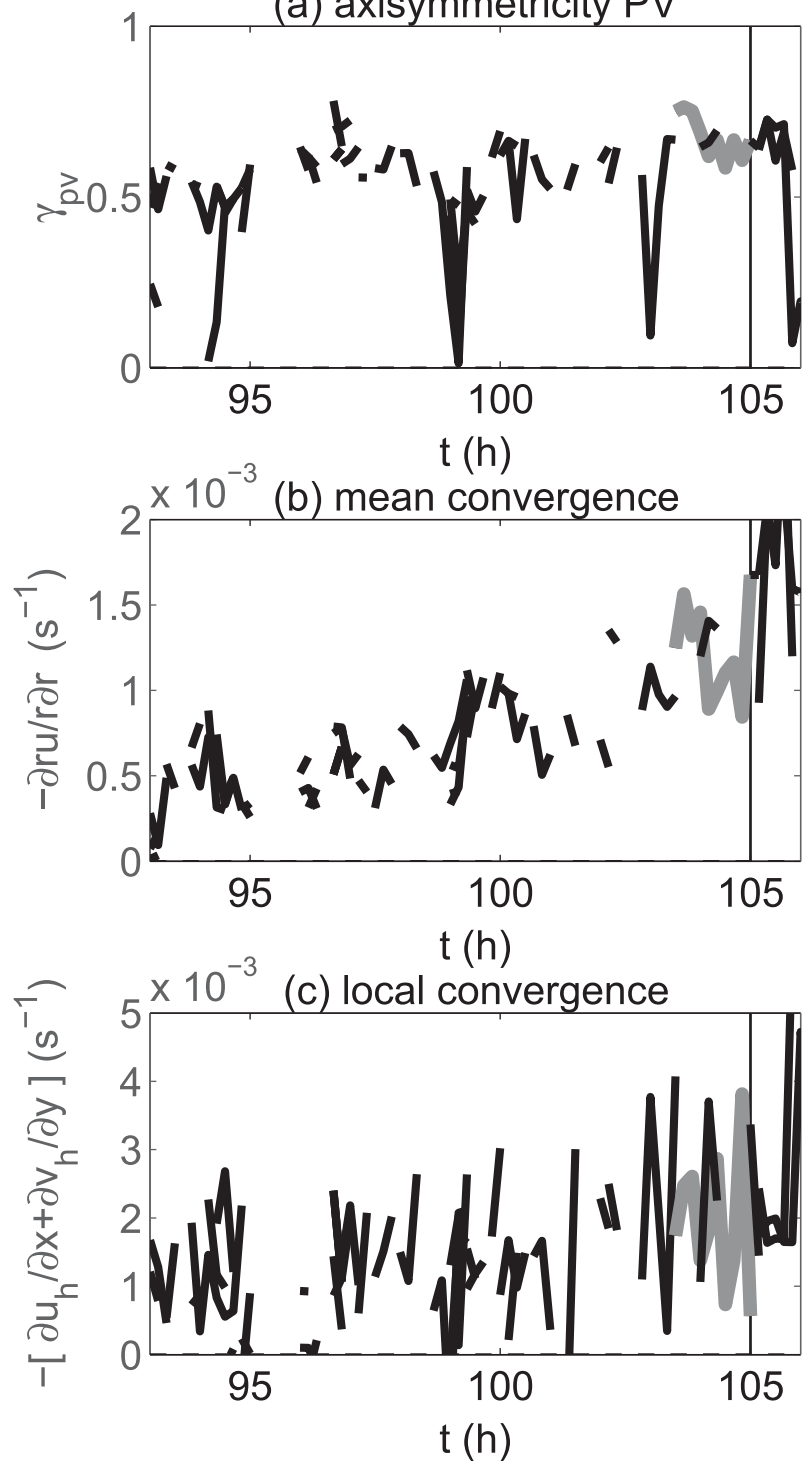

FIG. 12. Time series of the physical quantities of the detected convective cells: (a) the axisymmetricity for PV, (b) convergence of axisymmetric flow, and (c) convergence estimated by both the axisymmetric and asymmetric components. Quantities are estimated at the radius or at the azimuth where the cells are located. Convergences are vertically averaged below the $1-\mathrm{km}$ height. The gray line indicates the track of the cell that developed into the eyewall.

\section{Discussion}

\section{a. Proposed triggering mechanism for RI}

The results presented here indicate that RI of the TC commences immediately after the eyewall forms. The control run of MT13 revealed that the eyewall developed from a convective cell that was generated around the RMW a few hours before the onset of RI.

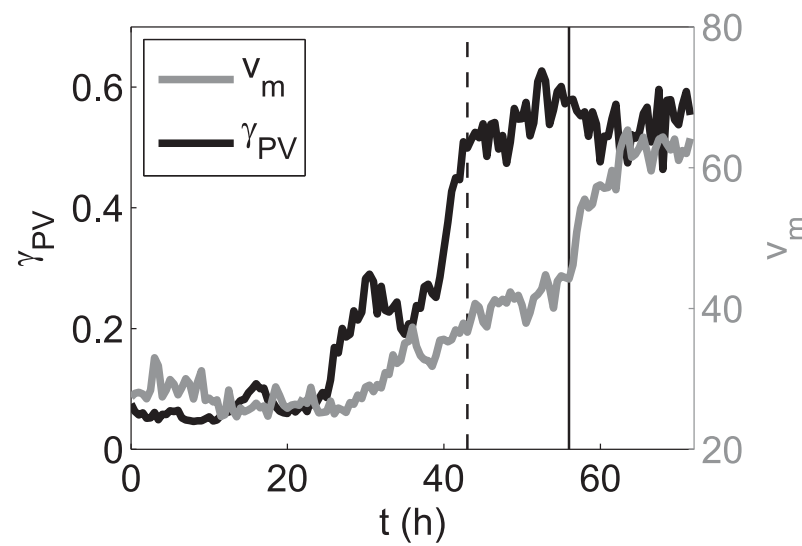

FIG. 13. As in Fig. 2, but for the realistic simulation of N13. The vertical dashed and solid lines indicate the time when the vortex becomes essentially axisymmetric $(t=44 \mathrm{~h})$ and when RI begins $(t=56 \mathrm{~h})$, respectively.

Many other convective cells appeared inside the RMW after the TC became nearly axisymmetric or the CAPE became large $(t=93-105 \mathrm{~h})$. The difference between the cell that developed and the others was the strong mass convergence in the boundary layer due to axisymmetric flow. Next, we discuss why convergence can intensify at the time when the cell is generated.

Using an axisymmetric balance model, Pendergrass and Willoughby (2009) demonstrated that the diabatic heating inside the RMW accelerates the tangential velocity at the RMW much more effectively than that

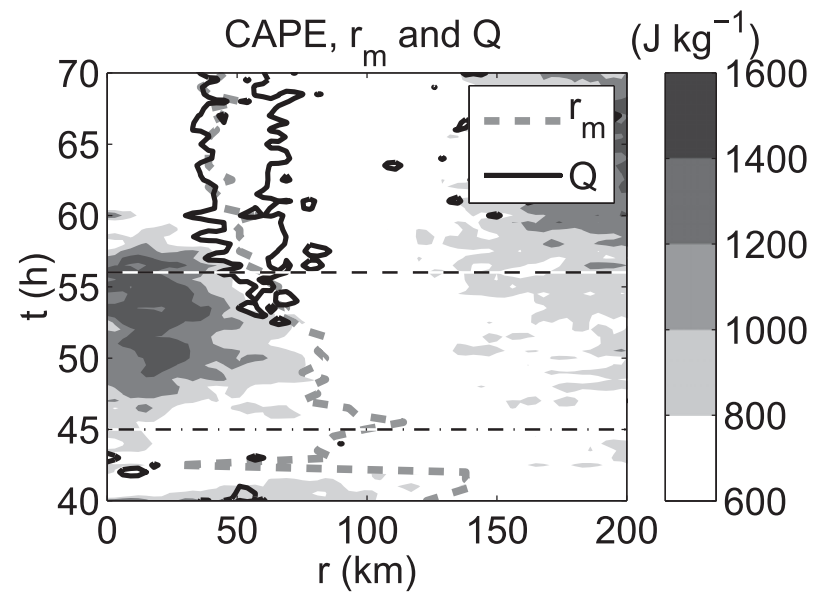

FIG. 14. Radius-time cross section of the CAPE (shaded), RMW (gray dashed line), and diabatic heating rate (black contour) of the realistic simulation of N13. The CAPE is calculated using averaged values in the lowest $500 \mathrm{~m}$. The diabatic heating rate is vertically averaged from $z=1.5$ to $12.0 \mathrm{~km}$. The contour represents $8 \mathrm{~K} \mathrm{~h}^{-1}$. Both the CAPE and heating rate are further averaged in the tangential direction. The dashed and dashed-dotted horizontal lines indicate the time when RI begins and when the TC becomes almost axisymmetric, respectively. 


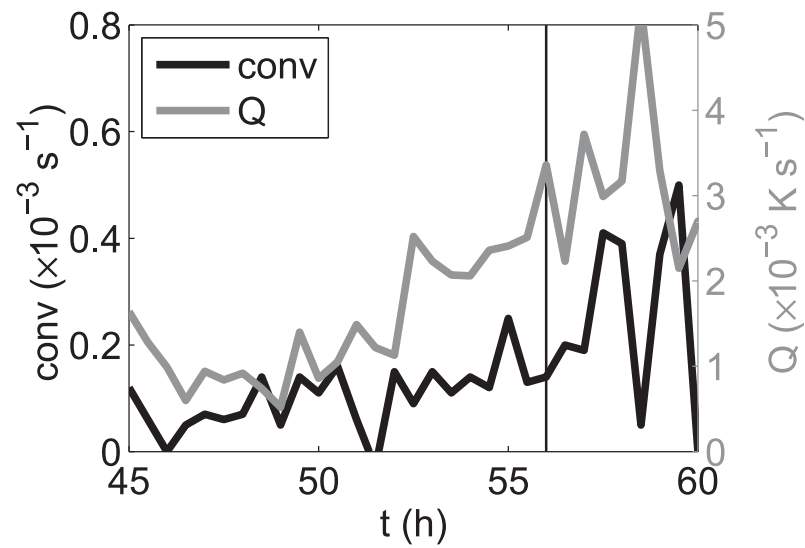

FIG. 15. As in Fig. 8, but for the realistic simulation of N13.

outside the RMW. Boundary layer theories for a welldeveloped steady cyclone involving no interaction with eyewall heating indicate that the boundary layer convergence along the secondary circulation tends to reach a maximum around the RMW (Kepert 2001; Kepert and Wang 2001; Smith et al. 2008). Because the two processes (i.e., diabatic heating in the eyewall and boundary layer convergence) are thought to be essential for TC intensification and, hence, to maintain an eyewall, it is likely that an eyewall will form inside, but not far from, the RMW.

According to the Ekman pumping theory for a rotating fluid on a frictional surface (Eliassen 1971; Eliassen and Lystad 1977; Montgomery et al. 2001; Kepert 2001), the pumping velocity is largest at the center of rotation in a fully linear system, whereas the pumping velocity peaks at a nonzero radius as nonlinear processes become more important [i.e., in a nonnegligible range of the Rossby number (Ro)]. The peak radius of the maximum Ekman pumping velocity is large when the Ro is large. Because the Ro can be defined as Ro $\equiv v_{m} /\left(r_{m} f\right)$, where $v_{m}, r_{m}$, and $f$ are the maximum tangential velocity, RMW, and Coriolis parameter, respectively, the radius of maximum pumping appears to temporally increase in an intensifying vortex. Thus, with increasing Ro or TC intensity, the radius increases from $r=0$ and approaches the RMW. Therefore, in weak TCs with a low Ro, the maximum convergence does not occur near the RMW but occurs far inside the RMW. In TCs with a strong intensity or a large Ro, strong convergence is present near the RMW.

Based on the results of this study and MT13, we propose the following triggering mechanism for the RI. First, a TC needs to be essentially axisymmetric. As an axisymmetric structure forms, the CAPE inside the RMW increases (Fig. 12 of MT13 and Fig. 14), which means that the thermodynamic condition is favorable for eyewall formation. As the TC slowly intensifies (i.e.,

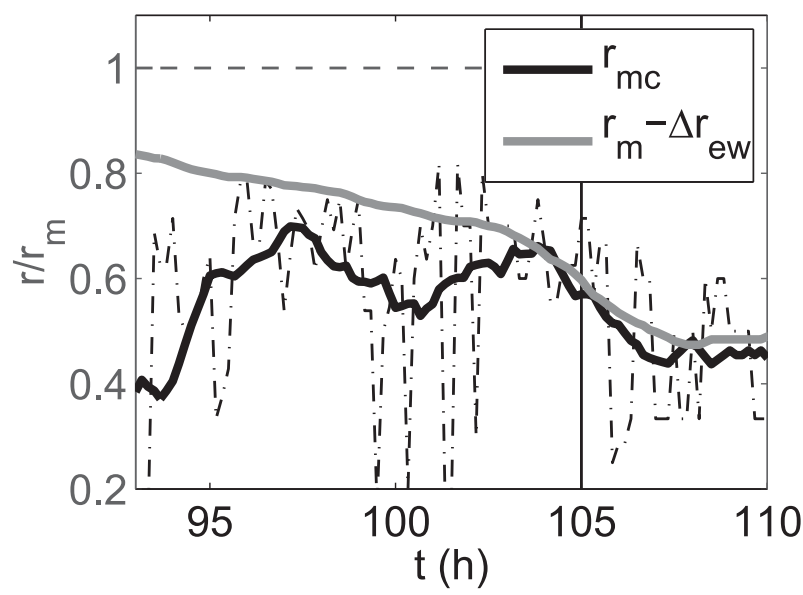

FIG. 16. Time series of the RMC (black lines) and the radius inside the RMW (gray line). Both are normalized by the RMW. The dashed-dotted line indicates the RMC at each moment, whereas the black solid line indicates the RMC filtered with a 1.5-h time window to remove fluctuations caused by local convection.

Ro increases), the radius of maximum Ekman pumping velocity, or the radius of maximum convergence (RMC), increases from the center. Once the radius approaches the RMW, it is dynamically favorable for eyewall formation. One or more convective cells in this region can develop into the eyewall, whereas a number of convective cells are generated in the core region after the core becomes thermodynamically favorable. After the axisymmetrized convective region (i.e., the eyewall) has formed, RI is initiated.

\section{b. Verification of the proposed mechanism by the idealized experiment and realistic simulation}

To confirm whether the proposed mechanism actually works in the simulated TCs, we analyzed the results of MT13 and N13. Figure 16 presents a time series of the $\mathrm{RMC}$ and the radius inside the distance of eyewall width from the RMW (=RMW $-\Delta r_{\mathrm{ew}}$, where $\Delta r_{\mathrm{ew}}$ is the eyewall width when it forms at $t=105 \mathrm{~h}$ ) in the idealized experiment. They were normalized by the RMW. As shown in the figure, the time series of unfiltered RMC fluctuates, apparently as a result of convection. To remove this temporal fluctuation, the RMC was temporally filtered by a 1.5 -h window, which was longer than the lifetime of the individual convection (the thick line). The distance between the RMC and the radius (RMW $\Delta r_{\text {ew }}$ ) shortened with time, and the RMC finally reached RMW $-\Delta r_{\mathrm{ew}}$ around $t=103.5 \mathrm{~h}$. Afterward, they remained very close to each other.

This important feature was also found in the results of N13. Figure 17 presents the same time series as that shown in Fig. 16, but it was obtained from the simulation of N13. The figure shows that the RMC was located far 


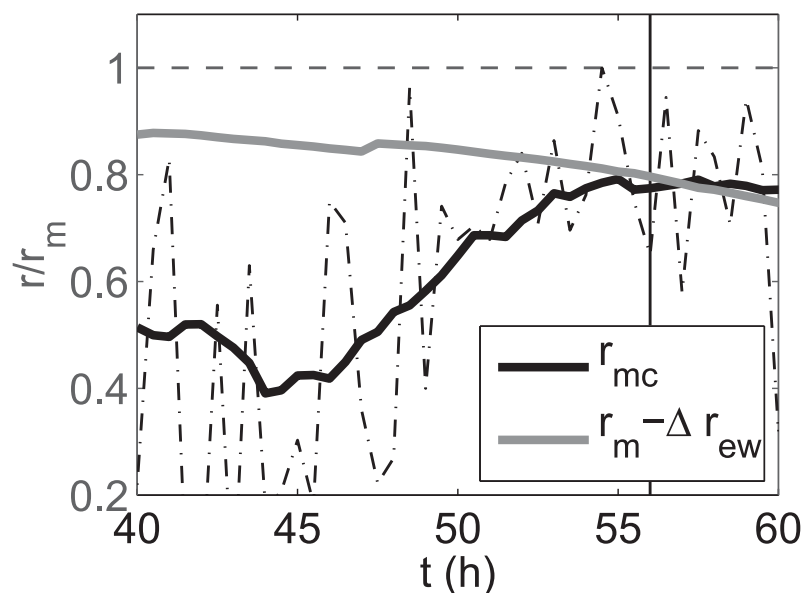

FIG. 17. As in Fig. 16, but for the realistic simulation of N13.

inside the RMW when the simulated TC became essentially axisymmetric $(t=44 \mathrm{~h})$. The RMC temporally increased, and it reached RMW $-\Delta r_{\text {ew }}$ a few hours before the onset of RI $(t=56 \mathrm{~h})$. It then coincided well with the RMW. The results obtained from the idealized experiment and the realistic simulation support the proposed triggering mechanism.

\section{c. Verification of the proposed mechanism using sensitivity experiments}

According to the TC boundary layer theory, the radial location of the maximum Ekman pumping velocity (i.e., RMC) increases with Ro. Hence, if the proposed mechanism actually works, TCs with a larger Ro will tend to enter the RI phase earlier, because the RMC departs from the rotation center earlier in a larger Ro.

To verify this hypothesis, we conducted a series of experiments to test the sensitivity to physical quantities related to Ro: the maximum tangential velocity of initial vortex $v_{m 0}$, its RMW $r_{m 0}$, and the Coriolis parameter that remains constant during integration $f_{0}$. The experimental settings of the sensitivity experiments were identical to those used in the control run of MT13 with the exception of these parameters. One of the three parameters was changed from the control run in a sensitivity experiment. Specifically, $v_{m 0}$ was changed from 10 to $25 \mathrm{~m} \mathrm{~s}^{-1}$ with an interval of $5 \mathrm{~m} \mathrm{~s}^{-1}, r_{m 0}$ was increased from 100 to $250 \mathrm{~km}$ with an interval of $50 \mathrm{~km}$, and $f_{0}$ was increased from $5 \times$ $10^{-5}$ to $15 \times 10^{-5} \mathrm{~s}^{-1}$ with an interval of $5 \times 10^{-5} \mathrm{~s}^{-1}$. The integration period was $150 \mathrm{~h}$.

Figure 18 presents a time series of TC intensities in the sensitivity experiments. All of the simulated TCs, except for the case of $f_{0}=15 \times 10^{-5} \mathrm{~s}^{-1}$, underwent RI and achieved a quasi-steady state. RI begins earlier under conditions of increasing $v_{m 0}$ or decreasing $r_{m 0}$ and $f_{0}$. The sensitivity to $f_{0}$ was consistent with that obtained by Li et al.

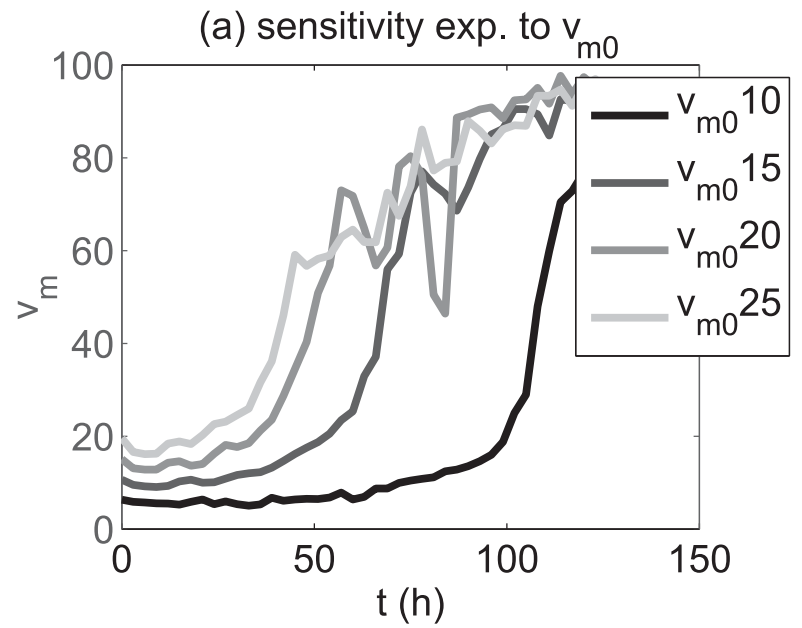

(b) sensitivity exp. to $r_{m 0}$

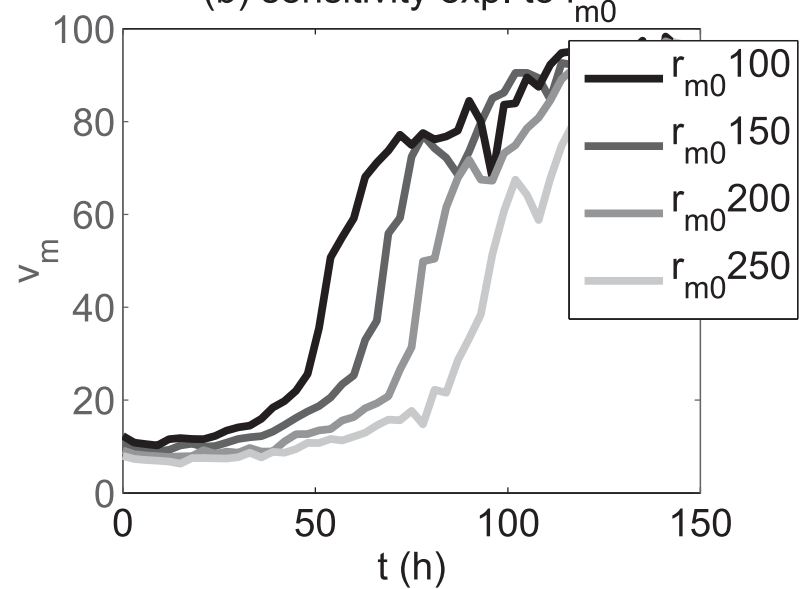

(c) sensitivity exp. to $f_{0}$

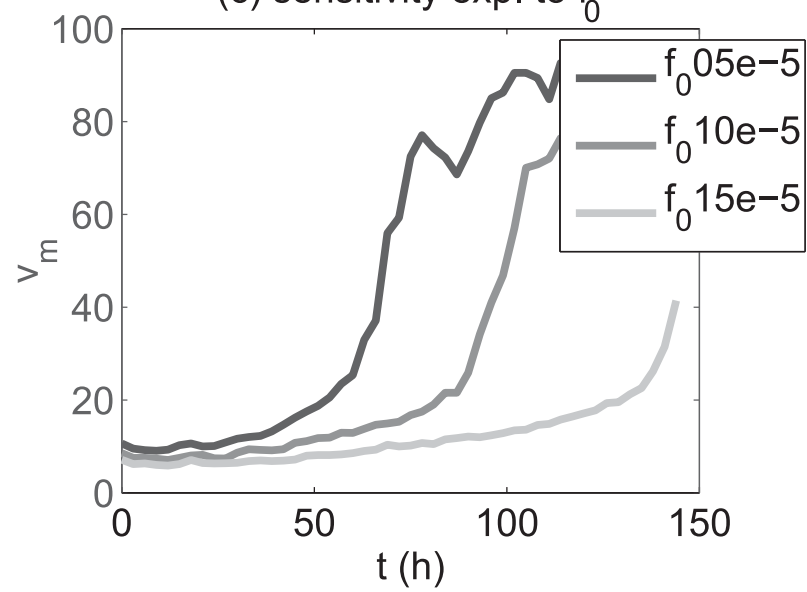

FIG. 18. Time series of the sensitivity of TC intensity to (a) the maximum tangential velocity of the initial vortex, (b) its RMW, and (c) the Coriolis parameter.

(2012), who also demonstrated that simulated TCs begin intensification earlier under conditions of smaller $f_{0}$ fields.

Figure 19 shows the RMC time series in all of the sensitivity experiments. On average, the RMC increased 


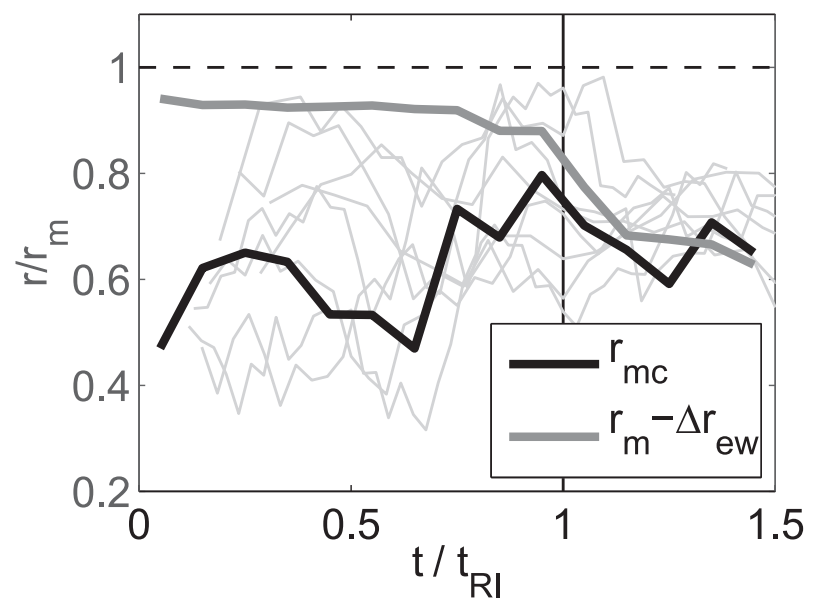

FIG. 19. As in Fig. 16, but for the sensitivity to $v_{m 0}, r_{m 0}$, and $f_{0}$ experiments. The thin gray lines indicate the sensitivity experiments, and the thick black line represents the ensemble mean. The time is normalized by the time of the onset of RI.

from $t / t_{\mathrm{RI}}=0.6$ and reaches the radius inside the distance of eyewall from the RMW ( $=$ RMW $\left.-\Delta r_{\text {ew }}\right)$ when the RI was initiated, $t=t_{\mathrm{RI}}$. The RMC thereafter follows this radius. Although there was some variability among the experiments, this result is overall consistent with the results obtained from the control run of MT13 and the N13 experiment.

Figure 20 presents the relationship between Ro [defined as Ro $\left.\equiv v_{m 0} /\left(r_{m 0} f_{0}\right)\right]$ and the time taken for the onset of RI in all of the sensitivity experiments. The figure clearly shows that the time required for the onset of RI is negatively correlated with Ro. Thus, TCs with a larger Ro tend to enter the RI phase earlier. In conclusion, these results support the robustness of the proposed mechanism and indicate that vortices with a larger Ro are more likely to experience RI.

\section{Conclusions}

We investigated the triggering mechanism for RI based on the results of an idealized numerical experiment (MT13) and a realistic simulation (N13), obtained from a three-dimensional nonhydrostatic model. Detailed analyses of the TC simulated in the idealized experiment revealed that the triggering process for RI in the TC was the formation of an eyewall. The eyewall formed $12 \mathrm{~h}$ after the TC became almost axisymmetric, as shown in MT13. In our study, a convective cell generated near the RMW $1.5 \mathrm{~h}$ before the onset of RI developed into the eyewall, whereas a number of cells were present inside the RMW after the axisymmetrization. The difference between the convective cell and the others was the strong mass convergence in the boundary

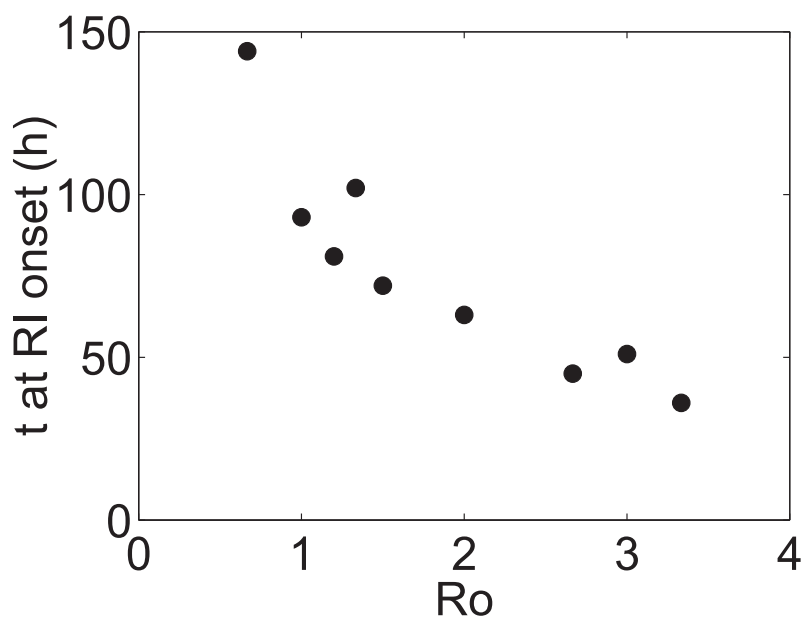

FIG. 20. Relationship between Ro $\equiv v_{m 0} /\left(r_{m 0} f_{0}\right)$ and the time of the onset of RI.

layer generated by axisymmetric flow. The results of the idealized experiment were consistent with those of the realistic simulation of $\mathrm{N} 13$.

Based on these results and the boundary layer theory for a rotating fluid developed in previous studies, we proposed the following triggering mechanism for RI: the TC needs to be essentially axisymmetric, and then the CAPE becomes large in the core region where the eyewall subsequently forms (MT13). At the time when the TC becomes essentially axisymmetric, the radius of maximum Ekman pumping velocity, or the maximum boundary layer convergence, is located far inside the TC compared with the RMW. The RMC temporally increases as the TC slowly intensifies after the axisymmetrization, and it finally reaches the RMW. Thus, the wavenumber- 0 component of boundary layer convergence appears around the RMW at this time and is dynamically favorable for producing a wavenumber- 0 convective cloud, an eyewall. RI commences after the circular region with large water content (indicating an eyewall) forms.

The proposed mechanism was supported by the results of the idealized experiment of MT13, the realistic simulation of $\mathrm{N} 13$, and a series of experiments that tested the sensitivity to quantities related to Ro (i.e., radius of maximum tangential velocity (RMW) and the Coriolis parameter in the initial state). The results of the sensitivity experiments revealed that, as Ro increases (initial TC intensity is large, initial RMW is small, and/or the Coriolis parameter is small), RI begins earlier. Because TCs develop from weak initial vortices, these results strongly suggest that Ro is a good indicator of whether the initial weak vortex undergoes RI.

It should be noted that the analysis of the triggering processes of RI is sensitive to the onset time. In this study, we defined the RI from the intensification rate, 
although the rate for the RI was very large (cf. Fig. 2) compared with the observations (e.g., Rogers et al. 2015). If the threshold for the onset of RI in Rogers et al. (2015) $\left(\sim 0.85 \mathrm{~m} \mathrm{~s}^{-1} \mathrm{~h}^{-1}\right)$ is applied, the onset of RI in the control run would be about $10 \mathrm{~h}$ earlier than in the present definition, and the results would be completely different.

Observations of RI are known to occur with asymmetric convection (Reasor et al. 2009; Molinari and Vollaro 2010; Guimond et al. 2010; Stevenson et al. 2014; Rogers et al. 2015). This study demonstrated the importance of the axisymmetric component of convective heating for the onset of RI. Future studies should examine the extent to which the present mechanism can be applied to TCs with large asymmetric components.

Acknowledgments. This study was partly supported by JSPS Scientific Research 20-776 for JSPS Research Fellows and General Collaborative Research \#24G-04 provided by the Disaster Prevention Research Institute, Kyoto University. We would like to express our gratitude to Prof. Dave Nolan, who kindly provided the nature run data of N13. We would also like to acknowledge the three anonymous reviewers for their helpful comments and fruitful discussion. We also thank Prof. Hirohiko Ishikawa and Dr. Junshi Ito for providing helpful comments.

\section{REFERENCES}

Barnes, G. M., and P. Fuentes, 2010: Eye excess energy and the rapid intensification of Hurricane Lili (2002). Mon. Wea. Rev., 138, 1446-1458, doi:10.1175/2009MWR3145.1.

Charney, J. G., and A. Eliassen, 1964: On the growth of the hurricane depression. J. Atmos. Sci., 21, 68-75, doi:10.1175/ 1520-0469(1964)021<0068:OTGOTH $>2.0 . \mathrm{CO} ; 2$.

Chen, H., and D.-L. Zhang, 2013: On the rapid intensification of Hurricane Wilma (2005). Part II: Convective bursts and the upper-level warm core. J. Atmos. Sci., 70, 146-162, doi:10.1175/JAS-D-12-062.1.

- — - J. Carton, and R. Atlas, 2011: On the rapid intensification of Hurricane Wilma (2005). Part I: Model prediction and structural changes. Wea. Forecasting, 26, 885-901, doi:10.1175/WAF-D-11-00001.1.

Davis, C., and Coauthors, 2008: Prediction of landfalling hurricanes with the advanced hurricane WRF model. Mon. Wea. Rev., 136, 1990-2005, doi:10.1175/2007MWR2085.1.

Donelan, M. A., B. K. Haus, N. Reul, W. J. Plant, M. Stiassnie, H. C. Graber, O. B. Brown, and E. S. Saltzman, 2004: On the limiting aerodynamic roughness of the ocean in very strong winds. Geophys. Res. Lett., 31, L18306, doi:10.1029/2004GL019460.

Dudhia, J., and Coauthors, 2008: Prediction of Atlantic tropical cyclones with the Advanced Hurricane WRF (AHW) Model.28th Conf. on Hurricanes and Tropical Meteorology, Orlando, FL, Amer. Meteor. Soc., 18A.2. [Available online at https://ams.confex.com/ ams/28Hurricanes/techprogram/paper_138004.htm.]

Eliassen, A., 1971: On the Ekman layer in a circular vortex. J. Meteor. Soc. Japan, 49, 784-789.

— numerical and theoretical study. Geophys. Norv., 31, 1-16.
Emanuel, K. A., 1986: An air-sea interaction theory for tropical cyclones. Part I: Steady-state maintenance. J. Atmos. Sci., 43, 585604, doi:10.1175/1520-0469(1986)043<0585:AASITF>2.0.CO;2.

_- 1995: The behavior of a simple hurricane model using a convective scheme based on subcloud-layer entropy equilibrium. J. Atmos. Sci., 52, 3960-3968, doi:10.1175/ 1520-0469(1995)052<3960:TBOASH > 2.0.CO;2.

_ 1997: Some aspects of hurricane inner-core dynamics and energetics. J. Atmos. Sci., 54, 1014-1026, doi:10.1175/ 1520-0469(1997)054<1014:SAOHIC >2.0.CO;2.

Guimond, S. R., G. M. Heymsfield, and F. J. Turk, 2010: Multiscale observations of Hurricane Dennis (2005): The effects of hot towers on rapid intensification. J. Atmos. Sci., 67, 633-654, doi:10.1175/2009JAS3119.1.

Harnos, D. S., and S. W. Nesbitt, 2011: Convective structure in rapidly intensifying tropical cyclones as depicted by passive microwave measurements. Geophys. Res. Lett., 38, L07805, doi:10.1029/2011GL047010.

Hong, S.-Y., Y. Noh, and J. Dudhia, 2006: A new vertical diffusion package with an explicit treatment of entrainment processes. Mon. Wea. Rev., 134, 2318-2341, doi:10.1175/MWR3199.1.

Iacono, M. J., J. S. Delamere, E. J. Mlawer, M. W. Shephard, S. A. Clough, and W. D. Collins, 2008: Radiative forcing by longlived greenhouse gases: Calculations with the AER radiative transfer models. J. Geophys. Res., 113, 1984-2012, doi:10.1029/ 2008JD009944.

Jiang, H., 2012: The relationship between tropical cyclone intensity change and the strength of inner-core convection. Mon. Wea. Rev., 140, 1164-1176, doi:10.1175/MWR-D-11-00134.1.

Jordan, C. L., 1958: Mean soundings for the West Indies area. J. Meteor., 15, 91-97, doi:10.1175/1520-0469(1958)015<0091: MSFTWI $>2.0 . \mathrm{CO} ; 2$.

Kain, J. S., 2004: The Kain-Fritsch convective parameterization: An update. J. Appl. Meteor., 43, 170-181, doi:10.1175/ 1520-0450(2004)043<0170:TKCPAU > 2.0.CO;2.

__ , and J. M. Fritsch, 1990: A one-dimensional entraining/ detraining plume model and its application in convective parameterization. J. Atmos. Sci., 47, 2784-2802, doi:10.1175/ 1520-0469(1990)047<2784:AODEPM>2.0.CO;2.

Kaplan, J., and M. DeMaria, 2003: Large-scale characteristics of rapidly intensifying tropical cyclones in the North Atlantic basin. Wea. Forecasting, 18, 1093-1108, doi:10.1175/ 1520-0434(2003)018<1093:LCORIT > 2.0.CO;2.

Kepert, J., 2001: The dynamics of boundary layer jets within the tropical cyclone core. Part I: Linear theory. J. Atmos. Sci., 58, 2469-2484, doi:10.1175/1520-0469(2001)058<2469:TDOBLJ >2.0.CO;2.

— , and Y. Wang, 2001: The dynamics of boundary layer jets within the tropical cyclone core. Part II: Nonlinear enhancement. J. Atmos. Sci., 58, 2485-2501, doi:10.1175/ 1520-0469(2001)058<2485:TDOBLJ > 2.0.CO;2.

Kessler, E., 1969: On the Distribution and Continuity of Water Substance in Atmospheric Circulation. Meteor. Monogr., No. 32, Amer. Meteor. Soc., 84 pp.

Kieper, M., and H. Jiang, 2012: Predicting tropical cyclone rapid intensification using the $37 \mathrm{GHz}$ ring pattern identified from passive microwave measurements. Geophys. Res. Lett., 39, L13804, doi:10.1029/2012GL052115.

Li, T., X. Ge, M. Peng, and W. Wang, 2012: Dependence of tropical cyclone intensification on the Coriolis parameter. Trop. $C y$ clone Res. Rev., 1, 242-253, doi:10.6057/2012TCRR02.04.

Lilly, D. K., 1962: On the numerical simulation of buoyant convection. Tellus, 14A, 148-172, doi:10.1111/ j.2153-3490.1962.tb00128.x. 
Lim, J.-O., and S.-Y. Hong, 2010: Development of an effective double-moment cloud microphysics scheme with prognostic cloud condensation nuclei $(\mathrm{CCN})$ for weather and climate models. Mon. Wea. Rev., 138, 1587-1612, doi:10.1175/ 2009MWR2968.1.

Miyamoto, Y., and T. Takemi, 2013: A transition mechanism for the axisymmetric spontaneous intensification of tropical cyclones. J. Atmos. Sci., 70, 112-129, doi:10.1175/ JAS-D-11-0285.1.

— , Y. Kajikawa, R. Yoshida, T. Yamaura, H. Yashiro, and H. Tomita, 2013: Deep moist atmospheric convection in a subkilometer global simulation. Geophys. Res. Lett., 40, 49224926, doi:10.1002/grl.50944.

— , R. Yoshida, T. Yamaura, H. Yashiro, H. Tomita, and Y. Kajikawa, 2015: Does convection vary in different cloudy disturbances? Atmos. Sci. Lett., doi:10.1002/asl2.558, in press.

Molinari, J., and D. Vollaro, 2010: Rapid intensification of a sheared tropical storm. Mon. Wea. Rev., 138, 3869-3885, doi:10.1175/2010MWR3378.1.

Montgomery, M. T., and R. K. Smith, 2014: Paradigms for tropical cyclone intensification. Aust. Meteor. Oceanogr. J., 64, 37-66.

- H. D. Snell, and Z. Yang, 2001: Axisymmetric spindown dynamics of hurricane-like vortices. J. Atmos. Sci., 58, 421-435, doi:10.1175/1520-0469(2001)058<0421:ASDOHL > 2.0.CO;2.

Noh, Y., W. G. Cheon, S. Y. Hong, and S. Raasch, 2003: Improvement of the K-profile model for the planetary boundary layer based on large eddy simulation data. Bound.-Layer Meteor., 107, 401-427, doi:10.1023/A:1022146015946.

Nolan, D. S., and L. D. Grasso, 2003: Nonhydrostatic, threedimensional perturbations to balanced, hurricane-like vortices. Part II: Symmetric response and nonlinear simulations. J. Atmos. Sci., 60, 2717-2745, doi:10.1175/ 1520-0469(2003)060<2717:NTPTBH >2.0.CO;2.

— , Y. Moon, and D. P. Stern, 2007: Tropical cyclone intensification from asymmetric convection: Energetics and efficiency. J. Atmos. Sci., 64, 3377-3405, doi:10.1175/JAS3988.1.

_- R. Atlas, K. T. Bhatia, and L. R. Bucci, 2013: Development and validation of a hurricane nature run using the joint OSSE nature run and the WRF Model. J. Adv. Model. Earth Syst., 5, 382-405, doi:10.1002/jame.20031.

Ogura, Y., 1964: Frictionally controlled, thermally driven circulations in a circular vortex with application to tropical cyclones. J. Atmos. Sci., 21, 610-621, doi:10.1175/1520-0469(1964)021<0610: FCTDCI $>2.0 . \mathrm{CO} ; 2$.

Ooyama, K., 1969: Numerical simulation of the life cycle of tropical cyclones. J. Atmos. Sci., 26, 3-40, doi:10.1175/ 1520-0469(1969)026<0003:NSOTLC $>2.0 . \mathrm{CO} ; 2$.

Pendergrass, A. G., and H. E. Willoughby, 2009: Diabatically induced secondary flows in tropical cyclones. Part I: Quasisteady forcing. Mon. Wea. Rev., 137, 805-821, doi:10.1175/ 2008MWR2657.1.

Persing, J., M. T. Montgomery, J. C. McWilliams, and R. K. Smith, 2013: Asymmetric and axisymmetric tropical cyclone dynamics. Atmos. Chem. Phys., 13, 12299-12341, doi:10.5194/ acp-13-12299-2013.

Reasor, P. D., and M. D. Eastin, 2012: Rapidly intensifying Hurricane Guillermo (1997). Part II: Resilience in shear. Mon. Wea. Rev., 140, 425-444, doi:10.1175/MWR-D-11-00080.1. , —, and J. F. Gamache, 2009: Rapidly intensifying Hurricane Guillermo (1997). Part I: Low-wavenumber structure and evolution. Mon. Wea. Rev., 137, 603-631, doi:10.1175/ 2008MWR2487.1.
Rogers, R., 2010: Convective-scale structure and evolution during a high-resolution simulation of tropical cyclone rapid intensification. J. Atmos. Sci., 67, 44-70, doi:10.1175/ 2009JAS3122.1.

_ vations of the inner-core structural differences between intensifying and steady-state tropical cyclones. Mon. Wea. Rev., 141, 2970-2991, doi:10.1175/MWR-D-12-00357.1.

,-- , and J. A. Zhang, 2015: Multiscale structure and evolution of Hurricane Earl (2010) during rapid intensification. Mon. Wea. Rev., 143, 536-562, doi:10.1175/ MWR-D-14-00175.1.

Rossow, W. B., and R. A. Schiffer, 1999: Advances in understanding clouds from ISCCP. Bull. Amer. Meteor. Soc., 80, 2261-2287, doi:10.1175/1520-0477(1999)080<2261: AIUCFI $>2.0 . \mathrm{CO} ; 2$.

Rotunno, R., and K. A. Emanuel, 1987: An air-sea interaction theory for tropical cyclones. Part II: Evolutionary study using a nonhydrostatic axisymmetric numerical model. J. Atmos. Sci., 44, 542-561, doi:10.1175/1520-0469(1987)044<0542: AAITFT $>2.0 . \mathrm{CO} ; 2$.

Schubert, W. H., and J. J. Hack, 1982: Inertial stability and tropical cyclone development. J. Atmos. Sci., 39, 1687-1697, doi:10.1175/1520-0469(1982)039<1687:ISATCD>2.0.CO;2.

Shapiro, L. J., and H. E. Willoughby, 1982: The response of balanced hurricanes to local sources of heat and momentum. J. Atmos. Sci., 39, 378-394, doi:10.1175/ 1520-0469(1982)039<0378:TROBHT>2.0.CO;2.

Sitkowski, M., and G. M. Barnes, 2009: Low-level thermodynamic, kinematic and reflectivity fields of Hurricane Guillermo (1997) during rapid intensification. Mon. Wea. Rev., 137, 645663, doi:10.1175/2008MWR2531.1.

Skamarock, W. C., J. B. Klemp, J. Dudhia, D. O. Gill, D. M. Barker, W. Wang, and J. G. Powers, 2008: A description of the Advanced Research WRF version 3. NCAR Tech. Note NCAR/TN-475+STR, 113 pp. [Available online at http:// www2.mmm.ucar.edu/wrf/users/docs/arw_v3.pdf.]

Smagorinsky, J., 1963: General circulation experiments with the primitive equations. I: The basic experiment. Mon. Wea. Rev., 91, 99-164, doi:10.1175/1520-0493(1963)091<0099: GCEWTP $>2.3 . \mathrm{CO} ; 2$.

Smith, R. K., M. T. Montgomery, and S. Vogl, 2008: A critique of Emanuel's hurricane model and potential intensity theory. Quart. J. Roy. Meteor. Soc., 134, 551-561, doi:10.1002/qj.241.

,-- , and N. Van Sang, 2009: Tropical cyclone spin-up revisited. Quart. J. Roy. Meteor. Soc., 135, 1321-1335, doi:10.1002/qj.428.

Stevenson, S. N., K. L. Corbosiero, and J. Molinari, 2014: The convective evolution and rapid intensification of Hurricane Earl (2010). Mon. Wea. Rev., 142, 4364-4380, doi:10.1175/ MWR-D-14-00078.1.

Van Sang, N., R. K. Smith, and M. T. Montgomery, 2008: Tropicalcyclone intensification and predictability in three dimensions. Quart. J. Roy. Meteor., 134, 563-582, doi:10.1002/qj.235.

Vigh, J. L., and W. H. Schubert, 2009: Rapid development of the tropical cyclone warm core. J. Atmos. Sci., 66, 3335-3350, doi:10.1175/2009JAS3092.1.

Willoughby, H. E., 2009: Diabatically induced secondary flows in tropical cyclones. Part II: Periodic forcing. Mon. Wea. Rev., 137, 822-835, doi:10.1175/2008MWR2658.1.

Zhang, D.-L., and H. Chen, 2012: Importance of the upper-level warm core in the rapid intensification of a tropical cyclone. Geophys. Res. Lett., 39, L02806, doi:10.1029/2011GL050578. 